Article

\title{
Surface Modification Effect and Electrochemical Performance of LiOH-High Surface Activated Carbon as a Cathode Material in EDLC
}

\author{
Zambaga Otgonbayar ${ }^{1}$, Sunhye Yang ${ }^{2,3}$, Ick-Jun Kim ${ }^{2}$ and Won-Chun Oh ${ }^{1,4, *}$ \\ 1 Department of Advanced Materials Science \& Engineering, Hanseo University, Seosan-si, \\ Chungnam 356-706, Korea; zambagaotgonbayar@gmail.com \\ 2 Korea Electrotechnology Reserch Institute, 12, Boolmosan-ro, 10beon-gil, Seongsan-gu, Changwon-si, \\ Gyeongsangnam-do 51543, Korea; shyang@keri.re.kr (S.Y.); ijkim@keri.re.kr (I.-J.K.) \\ 3 Department of Chemical Engineering, Inha University, 100 Inha-ro, Michuhol-gu, Incheon 22212, Korea \\ 4 Anhui International Joint Research Center for Nano Carbon-based Materials and Environmental Health, \\ College of Materials Science and Engineering, Anhui University of Science \& Technology, \\ Huainan 232001, China \\ * Correspondence: wc_oh@hanseo.ac.kr; Tel.: +82-010-3775-9289
}

Citation: Otgonbayar, Z.; Yang, S.;

Kim, I.-J.; Oh, W.-C. Surface

Modification Effect and

Electrochemical Performance of LiOH-High Surface Activated Carbon as a Cathode Material in EDLC.

Molecules 2021, 26, 2187. https:// doi.org/10.3390/molecules26082187

Academic Editor: Chan Kyung Kim

Received: 26 February 2021

Accepted: 7 April 2021

Published: 10 April 2021

Publisher's Note: MDPI stays neutral with regard to jurisdictional claims in published maps and institutional affiliations.

Copyright: (c) 2021 by the authors. Licensee MDPI, Basel, Switzerland. This article is an open access article distributed under the terms and conditions of the Creative Commons Attribution (CC BY) license (https:/ / creativecommons.org/licenses/by/ $4.0 /)$.

\begin{abstract}
This study aimed to improve the performance of the activated carbon-based cathode by increasing the Li content and to analyze the effect of the combination of carbon and oxidizing agent. The crystal structure and chemical structure phase of Li-high surface area activated carbon material (Li-HSAC) was analyzed by X-ray diffraction (XRD) and Raman spectroscopy, the surface state and quantitative element by scanning electron microscopy with energy dispersive $\mathrm{X}$-ray spectroscopy (SEM-EDX) and the surface properties with pore-size distribution by Brunauer-Emmett-Teller (BET), Barrett-Joyner-Halenda (BJH) and t-plot methods. The specific surface area of the Li-YP80F is $1063.2 \mathrm{~m}^{2} / \mathrm{g}$, micropore volume value is $0.511 \mathrm{~cm}^{3} / \mathrm{g}$ and mesopore volume is $0.143 \mathrm{~cm}^{3} / \mathrm{g}$, and these all values are higher than other $\mathrm{LiOH}$-treated carbon. The surface functional group was analyzed by a Boehm titration, and the higher number of acidic groups compared to the target facilitated the improved electrolyte permeability, reduced the interface resistance and increased the electrochemical properties of the cathode. The oxidizing agent of $\mathrm{LiOH}$ treated high surface area of activated carbon was used for the cathode material for EDLC (electric double layer capacitor) to determine its electrochemical properties and the as-prepared electrode retained excellent performance after 10 cycles and 100 cycles. The anodic and cathodic peak current value and peak segregation of Li-YP80F were better than those of the other two samples, due to the micropore-size and physical properties of the sample. The oxidation peak current value appeared at $0.0055 \mathrm{~mA} / \mathrm{cm}^{2}$ current density and the reduction peak value at $-0.0014 \mathrm{~mA} / \mathrm{cm}^{2}$, when the Li-YP80F sample used to the $\mathrm{Cu}$-foil surface. The redox peaks appeared at $0.0025 \mathrm{~mA} / \mathrm{cm}^{2}$ and $-0.0009 \mathrm{~mA} / \mathrm{cm}^{2}$, in the case of using a Nickel foil, after 10 cycling test. The electrochemical stability of cathode materials was tested by 100 recycling tests. After 100 recycling tests, peak current drop decreased the peak profile became stable. The LiOH-treated high surface area of activated carbon had synergistically upgraded electrochemical activity and superior cycling stability that were demonstrated in EDLC.
\end{abstract}

Keywords: LiOH-treatment; high surface area of activated carbon; cathode material; electrochemical performance

\section{Introduction}

Activated carbon (AC) has specific properties, such as high specific area, balanced conductivity, high volume of porous structure and high stability in acidic condition $(\mathrm{pH} \leq 7)$, that potentially make it an ideal material for the half-cell electrode [1-5]. Graphitic material is mostly used as a high-efficient electrode-material. The properties of high surface area activated carbon (HSAC) can be further re-shaped to instigate specific advantageous 
activation properties [6-8]. However, the elasticity of the carbon surface hinders absorption of the electrolyte into the electrode and weakens the output properties of the hybrid electrode due to the poor wettability on the carbon surface. Therefore, it is important to improve the hydrophilicity and output properties of the hybrid electrode through surface modification containing acidic functional-groups to meliorate the wetting properties of the water [9]. The surface is generally modified using chemical reagents such as $\mathrm{KMnO}_{4}, \mathrm{H}_{2} \mathrm{O}_{2}$, $\mathrm{NaOH}$ and $\mathrm{LiOH}$ [10-12] due to the various specifications for the activity of AC [13-15]. Alkaline hydroxide can be used as an activating agent to create a porous structure at high temperature [16].

The creation of the porous structure and surface modification is the most widely used method of improving the electrochemical properties of the activated carbon (AC). If an AC with an enormous surface area is used as a substrate and is reacted with lithium hydroxide $(\mathrm{LiOH})$ or potassium hydroxide $(\mathrm{KOH})$ under high-temperature conditions, an HSAC with a large micropore structure may be obtained. In order to increase the number of hydrophilic groups or change the activated carbon surface to hydrophilicity, acidic treatment and oxidizing agents capable of reducing the number of basic functional groups are used. In addition, a hydrophilic metal oxide (transition metal-based semiconducting oxide) is introduced to increase the wettability, electron transfer, and ion transfer effects of the hybrid electrode. Surface hydrophilicity control technology requires advanced carbon technology and evaluation technology. Developing these technologies quickly will require a batch-type hydrothermal synthesis method and a raw material control technology by microwave method that can support fast mass production $[17,18]$. The improvement of the output and long-term reliability of the hybrid capacitor depends on the surface control technology of AC and the conductive material.

The following sub-groups are important goals of this research: (a) surface hydrophilicity control technology improves the output characteristics by improving the electrolyte impregnation at the interface of the electrode and activated carbon and reducing the interface resistance, (b) improves the long-term reliability of the cell by inhibiting the corrosion of the hydrogen storage material of the cathode through the hydrophilicity control technology and catalytic function technology of the activated carbon surface, and (c) batch-type hydrothermal synthesis and microwave control technology for mass production.

In this study, LiOH- treated HSACs were successfully synthesized with surface modification that can activate the ion transfer and electrolyte impregnation. The phase structure, surface morphology, element analysis, functional groups, and electro-chemical properties of the modified (including surface coating and surface structure modification) activated carbon were analysed using XRD, SEM, EDX, FTIR, BET and a Potentiastat apparatus. $\mathrm{LiOH}$-treated carbon material used for the working electrode. As-prepared Li-YP80F sample proved to have exceptional electrochemical performance, with high pore distribution and specific surface area. A LiOH-treated HSAC had good stability under a 10 and 100-cycling test. The peak current density and peak separation profile was good in Li-YP80F sample. A Li-YP80F electrode had good stability under a 100-cycle test. By comparing these three cycling performance curves, it can be seen that there is a process of activating capacity that happens during the first cycles. This approach presented herein offers a promising route for the rational design of a new class of supercapacitors.

\section{Results}

\subsection{Crystallography and Morphology Analysis}

The XRD pattern of LiOH-treated high surface area of activated carbon after heat treatment at $600{ }^{\circ} \mathrm{C}$ is shown in Figure 1. Figure 1a shows the XRD-pattern of Li-graphite, $\mathrm{Li}-\mathrm{YP50F}$ and Li-YP80F. In all three samples, the clearest peak corresponded to the XRD pattern of $\mathrm{Li}_{2} \mathrm{CO}_{3}$. The diffraction peaks at 20 degrees of $21.46^{\circ}, 29.52^{\circ}, 30.63^{\circ}, 32.0^{\circ}, 34.22^{\circ}$, $36.95^{\circ}$, and $59.91^{\circ}$ equated to the (110) (111) (202) (002) (112) (311) and (204) crystal planes of $\mathrm{Li}_{2} \mathrm{CO}_{3}$ (JCPDS. 22-1141). XRD peaks associated with $\mathrm{Li}_{2} \mathrm{O}, \mathrm{LiC}$ and $\mathrm{Li}$-composite were also observed, possibly due to the side reaction between the oxidizing agent and carbon 
material. These side peaks belonged to the XRD pattern of $\mathrm{Li}_{2} \mathrm{O}$ (JCPDS. 09-0355), $\mathrm{LiC}$ (JCPDS. 14-0649) and Li (JCPDS.15-1401).
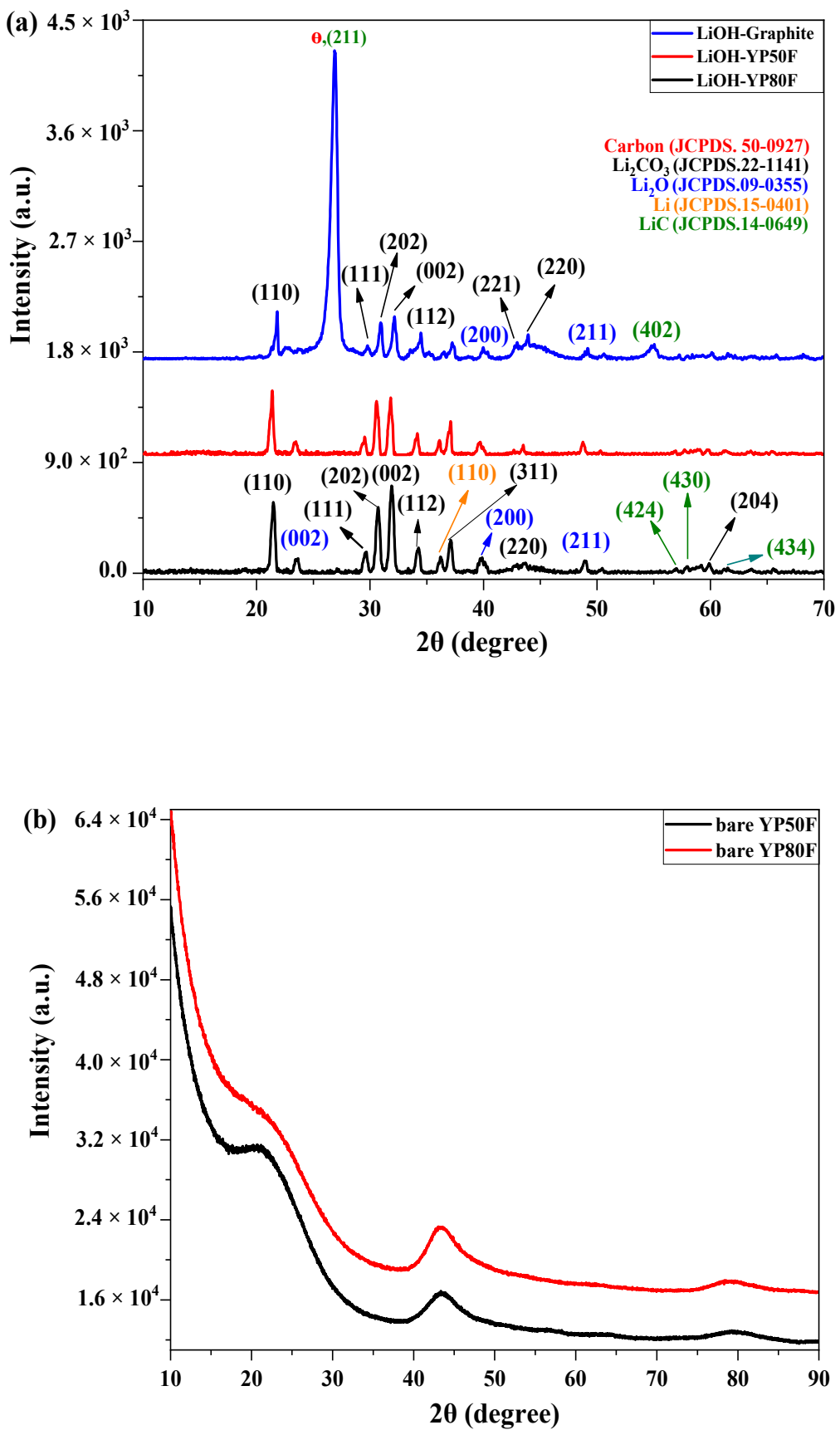

Figure 1. XRD result of (a) LiOH-treated YP80F, YP50F and graphite, (b) bare YP80F and YP50F.

The XRD pattern of Li-Graphite exhibited one sharp peak at $26.78^{\circ}$, which is a member of graphite and lithium carbide. XRD graphs of the pure YP50F and YP80F are displayed in Figure 1b. Comparison of these results revealed the lithium-carbon nature of the Li-HSAC samples, which confirmed the successful synthesis of the final sample.

The surface state and morphology analysis of the samples are displayed in Figure 2. The $\mathrm{LiOH}$ treatment with high-temperature calcination completely changed the surface structure of the samples. The oxidizing agent was irregularly agglomerated and successfully up-loaded on the surface of the carbon materials due to the surface functional group. The quantitative analysis of the main element was analyzed by an EDX measurement incorporated by SEM. 


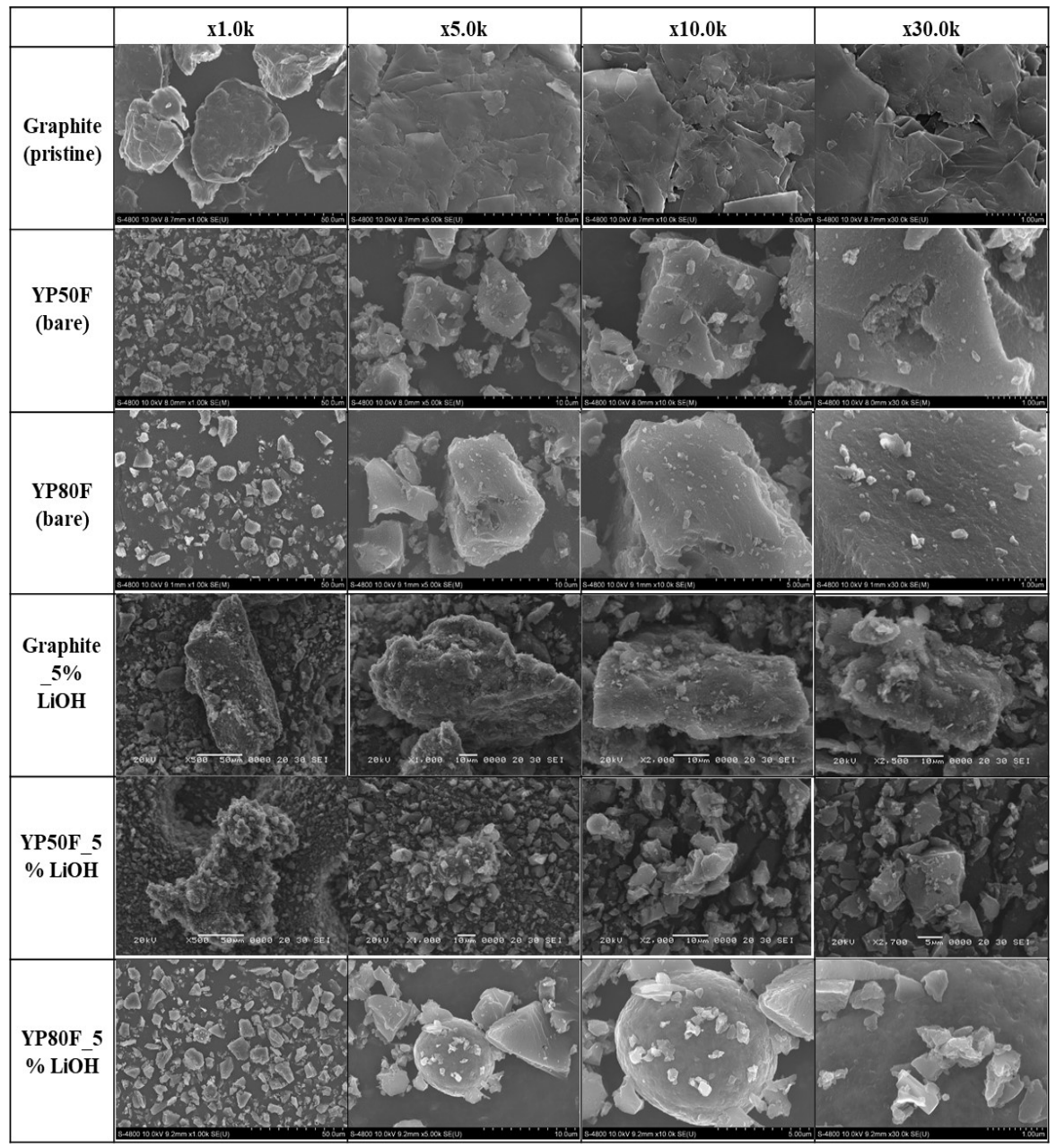

Figure 2. SEM images of bare graphite (pristine), YP50F, YP80F, graphite-LiOH, YP50F-LiOH and YP80F-LiOH.

Figure 3 shows the presence of the main elements of the samples. The $\mathrm{C}$ element is the principal element of the carbon and the $\mathrm{O}$ is the main element of the oxidizing agent. The main element of the oxidizing agent was obtained. This result confirmed the atomic weight of the main elements in the final samples. The crystallinity and SEM analyses of the agent's distribution confirmed that it was successfully up-loaded. The results indicated that the re-structuring may modify the performance of the bare high surface area of activated carbon.

\subsection{The Functional Group and Surface Area Analysis}

The study of how the surface and functional group of a carbon material changes after $\mathrm{LiOH}$ treatment and calcification will determine how the material interacts with alkaline electrolyte ions. The surface functional group and surface area with pore distribution of the samples were analyzed by a Boehm titration and $\mathrm{N}_{2}$-adsorption-desoprtion isotherm. Boehm titration is an acid-base titration method that is used to determine the number of surface oxygen groups (acidic or basic) present on $\mathrm{LiOH}$-treated carbon surfaces. This method is usually used complementary with other methods such as Fourier Transform Infrared Spectroscopy (FTIR).

In the titration, three different sodium-based solutions were used to neutralize the functional groups. Specifically, $\mathrm{NaOH}$ neutralizes the Bronsted acid group, $\mathrm{NaHCO}_{3}$ and $\mathrm{Na}_{2} \mathrm{CO}_{3}$ neutralize the carboxylic acid and lactonic groups, and this neutralization activity depends on the pKa of each solution [19]. To analyze the quantitative of functional group, Equations (8) and (9) were used and the data are summarized in Table 1. According to 
the titration results, the values of the surface functional groups were greater than the purpose of this study, which demonstrated that our $\mathrm{LiOH}$-treatment experiments provided a proportionate number of acidic functional groups on the carbon surface and reduced the radical functional-groups, as shown in Figure 4. Depending on the ratio of acidic and basic-groups, the electrolyte impregnation at the interface of the working electrode can be improved, and the interface resistance can be reduced. The surface chemistry of the high surface area of AC strongly affects the electrochemical measurement. According to previous research, the surface functional group on porous-structured carbon material can achieve a high charge-storage and electrochemical performance [20-23]. In addition, the number of functional groups was increased by nitric acid treatment, which enhanced the wettability and increased the capacitance in acid and base-electrolyte solutions [24]. Furthermore, our analysis results confirmed that Li-HSAC had numerous acidic functional groups which can favorably act-on the diffusion and transport of the alkaline electrolyte ions.

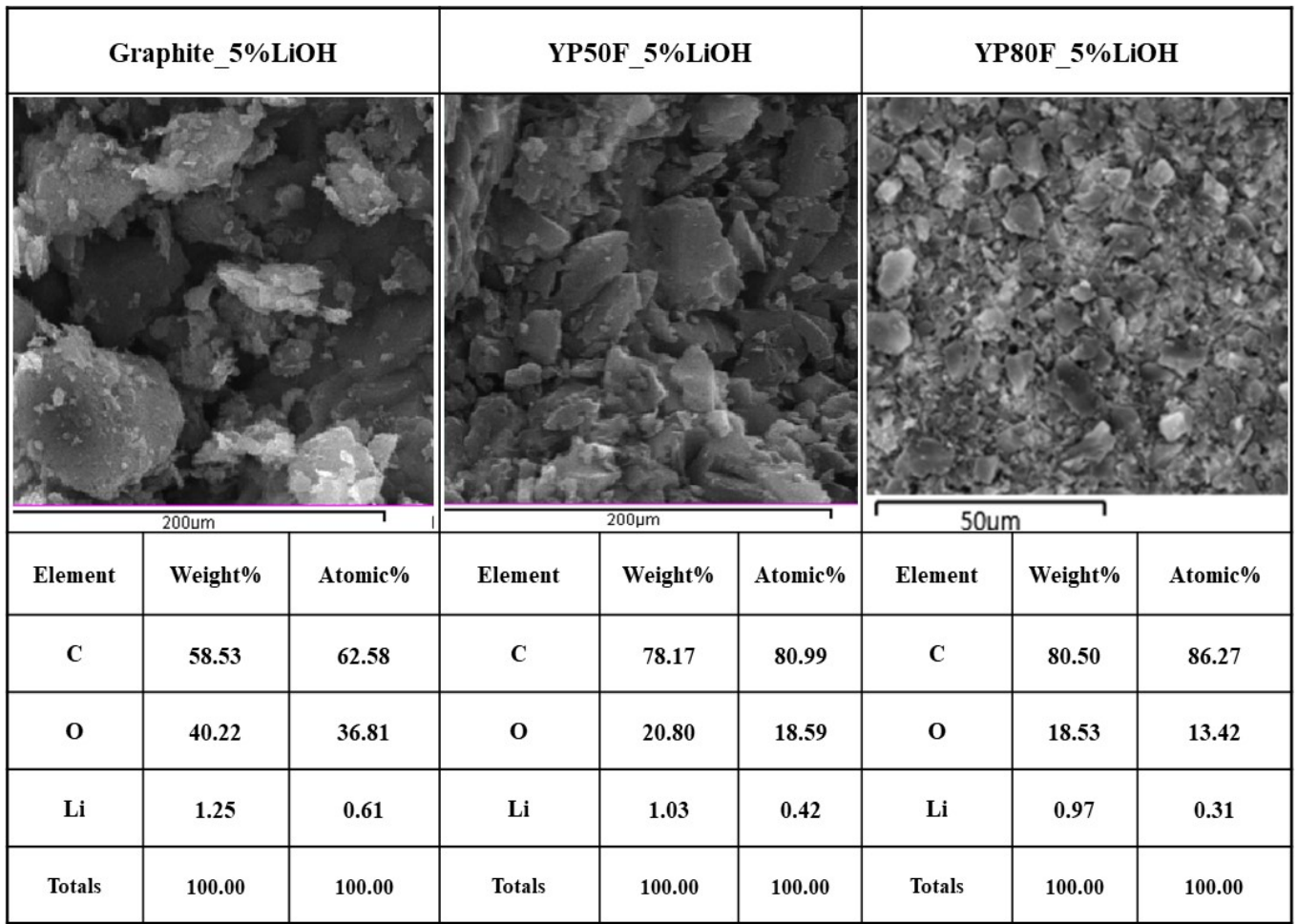

Figure 3. EDAX analysis of LiOH-treated YP50F, YP80F and graphite.

Table 1. Surface functional group analysis of the LiOH-treated carbon materials.

\begin{tabular}{cccccccccc}
\hline & & \multicolumn{3}{c}{ Surface Functional Group (mg/g) } & \multicolumn{3}{c}{ Surface Functional Group (mmol/g) } \\
\cline { 3 - 10 } & & Carboxylic & Lactonic & Phenolic & $\begin{array}{c}\text { Total } \\
\text { acidic }\end{array}$ & Carboxylic & Lactonic & Phenolic $\begin{array}{c}\text { Total } \\
\text { Acidic }\end{array}$ \\
\hline 1 & LiOH-treated YP80F & 27.58 & 8.33 & 11.44 & 47.35 & 0.123 & 0.033 & 0.121 & 0.278 \\
\hline 2 & $\begin{array}{c}\text { LiOH-treated } \\
\text { Graphite }\end{array}$ & 28.48 & 7.82 & 11.48 & 47.78 & 0.127 & 0.030 & 0.122 & 0.279 \\
\hline 3 & LiOH-treated YP50F & 28.21 & 8.13 & 11.86 & 48.20 & 0.126 & 0.032 & 0.123 & 0.281 \\
\hline
\end{tabular}



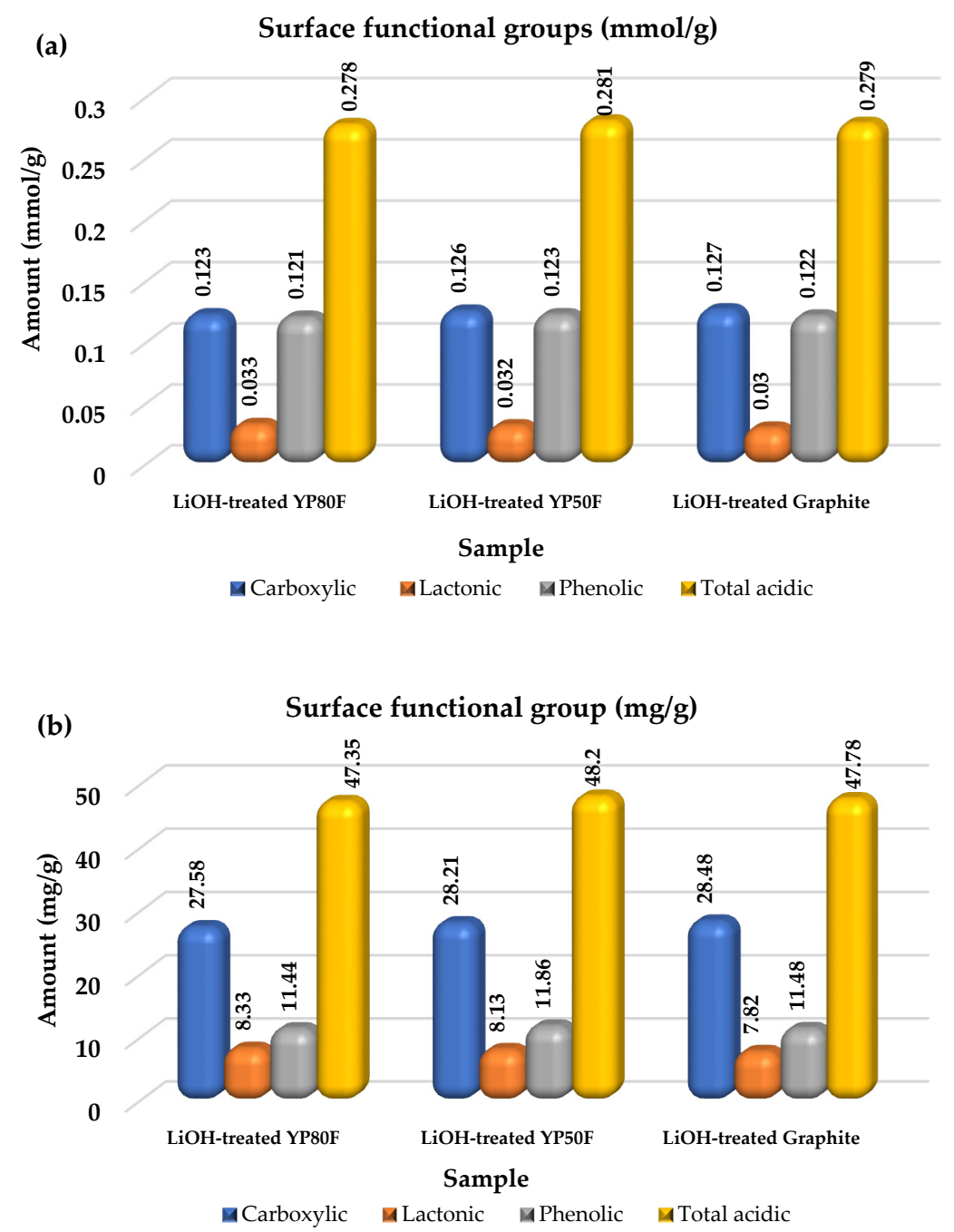

Figure 4. Boehm titration result of LiOH-treated YP80F, YP50F and graphite. (a) mmol/g unit, and (b) $\mathrm{mg} / \mathrm{g}$ unit.

The chemical bond vibration and the functional group were analyzed by FTIR, which is based on an attenuated total-reflection (ATR) method. Figure 5 shows the FTIR spectrum of the samples, which consisted of three main peaks. The main peaks of the carbon material were observed at around 1400 and $3000 \mathrm{~cm}^{-1}$ wavenumber regions. The presence of the lithium peak was observed at around $850 \mathrm{~cm}^{-1}$ region. The peak face of Li-graphite was different because the lithium peak was not observed. The pore-size, volume and specific surface area were analyzed by an $\mathrm{N}_{2}$-adsorption-desorption isotherm.

Figure 6 shows the nitrogen adsorption-desorption isotherms of Li-YP50F, Li-YP80F and graphite. The electrochemical properties of nanocomposites were correlated with the $\mathrm{BJH}$ and BET analysis results. The relative pressure of the analysis was $0.4-1.0 \mathrm{P} / \mathrm{P}_{0}$, and the relevance between pore-division and isotherm classified to the H1-type. The H1-type identifies the narrow pore-size state of the material. HSAC with large micropore structure may be obtained due to the $\mathrm{LiOH}$ agent and high temperature calcination. From BET analysis, the total pore volume and mean pore diameter of raw carbon material is reduced due to the oxidizing agent treatment. $\mathrm{LiOH}$-oxidizing agent gathered in the disordered pore structure of the YP50F and YP80F. In the case of the graphite, the LiOH located on the surface. The pore distribution of the $\mathrm{LiOH}$-treated samples was analyzed by BJH and T-plot method. According from the result, mesopore and micropore volumes and pore surface area were decreased. The micropore volume and surface area of the YP80F was high, the high amount of LiOH-oxidizing agent can inter-collected in the pore. The inter-collected 
amount of the $\mathrm{LiOH}$ can positively improve the $\mathrm{Li}+$ ion transition between cathode and anode of EDLC, then it can upgrade the performance of the EDLC material.

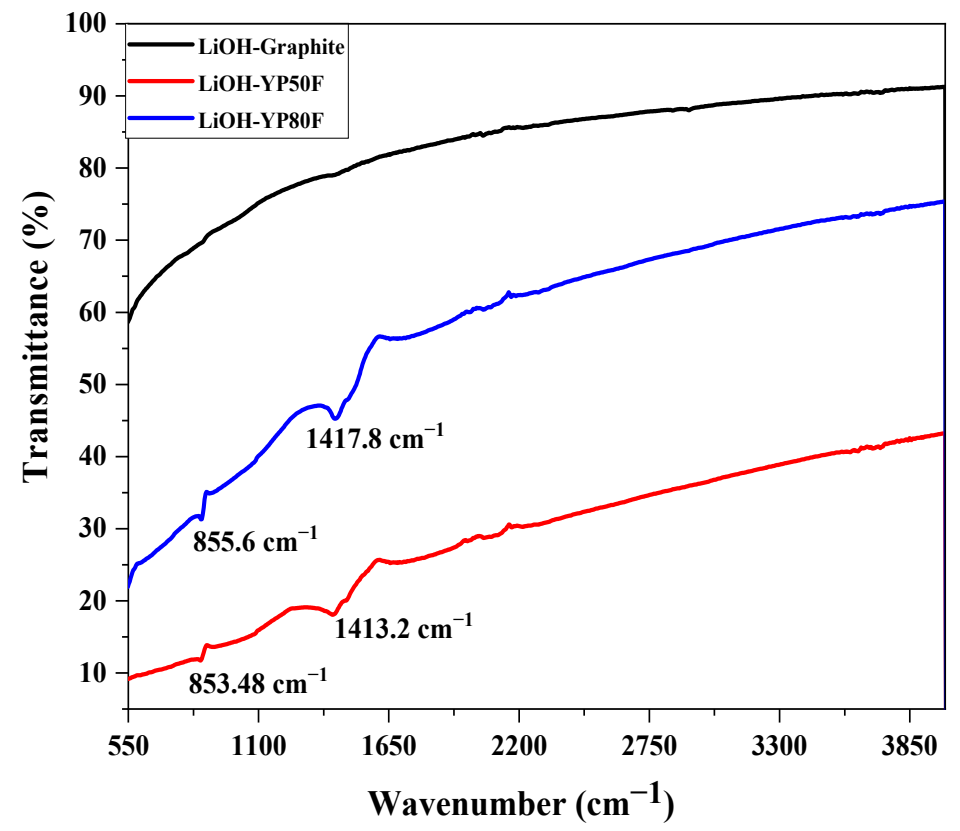

Figure 5. FTIR spectra of LiOH-treated YP80F, YP50F and graphite.

The results of Li-HSAC pore-volume and specific surface area are summarized in Table 2. According to the summary results of BET and BJH, the surface area and total pore mass (mesopore and micropore) of the graphite was increased after the $\mathrm{LiOH}$ treatment, whereas the values were decreased for the bare-YP50F and YP80F. In the calculation of the $\mathrm{t}$ plot, the total surface area of Li-YP50F was $43.5 \mathrm{~m}^{2} / \mathrm{g}$ and of Li-YP80F was $1063.2 \mathrm{~m}^{2} / \mathrm{g}$. The micropore volume of Li-YP80F decreased from 1.084 to $0.511 \mathrm{~cm}^{3} / \mathrm{g}$, while the mesopore volume increased from 0.100 to $0.143 \mathrm{~cm}^{3} / \mathrm{g}$. The BET and BJH analysis results showed a similar decrease in the two main samples. The mesopore size and specific surface area were noticeably reduced after $\mathrm{LiOH}$-treatment and calcination process. The micro-sized pore state and high surface area are the main parameters that are valuable for framing ion-transport tunnels in electro chemical reactions.

Furthermore, the surface acidic group can improve the utilization rate of the electrode by facilitating the passage of ions into the micro-pores and improving the surface utilization rate of the pores. Based on these analysis results, the volume of the pore-distribution (micro, meso) reduced, which negatively affect the ion transport of the $\mathrm{KOH}$ electrolyte. However, the presence of the surface acidic group can enhance the ion-transport through the enhanced micropore structure of the Li-HSAC material, because the acidic group can improve the wettability and electronegativity, which in turn affect the electrolyte impregnation. In addition, the Li-YP80F sample had high surface area, which demonstrated the more active interfacial site between the alkaline electrolyte and the cathode. Previous studies have shown that the surface area and pore size are the main factors influencing the performance of the electrode material $[25,26]$. The micropore-structured carbon material showed a high capacitance with continuous charge and discharge due to the oxygen-containing functional group. The specific capacitance of the $\mathrm{LiOH}$-treated graphite, YP50F and YP80F carbon were calculated, and all analysis results are summarized in Table 3. According to the analysis result, the Li-YP80F sample had a high value of specific capacitance and integration area. This sample had high number of micropore distribution and high surface area with hydrophilicity, and the porous (micro) structure with a high surface of carbon material is an ideal material for the electrode on the EDLC. All of the above factors are 
present in the Li-YP80F material, which confirmed that the Li-YP80F sample had high electrochemical properties.
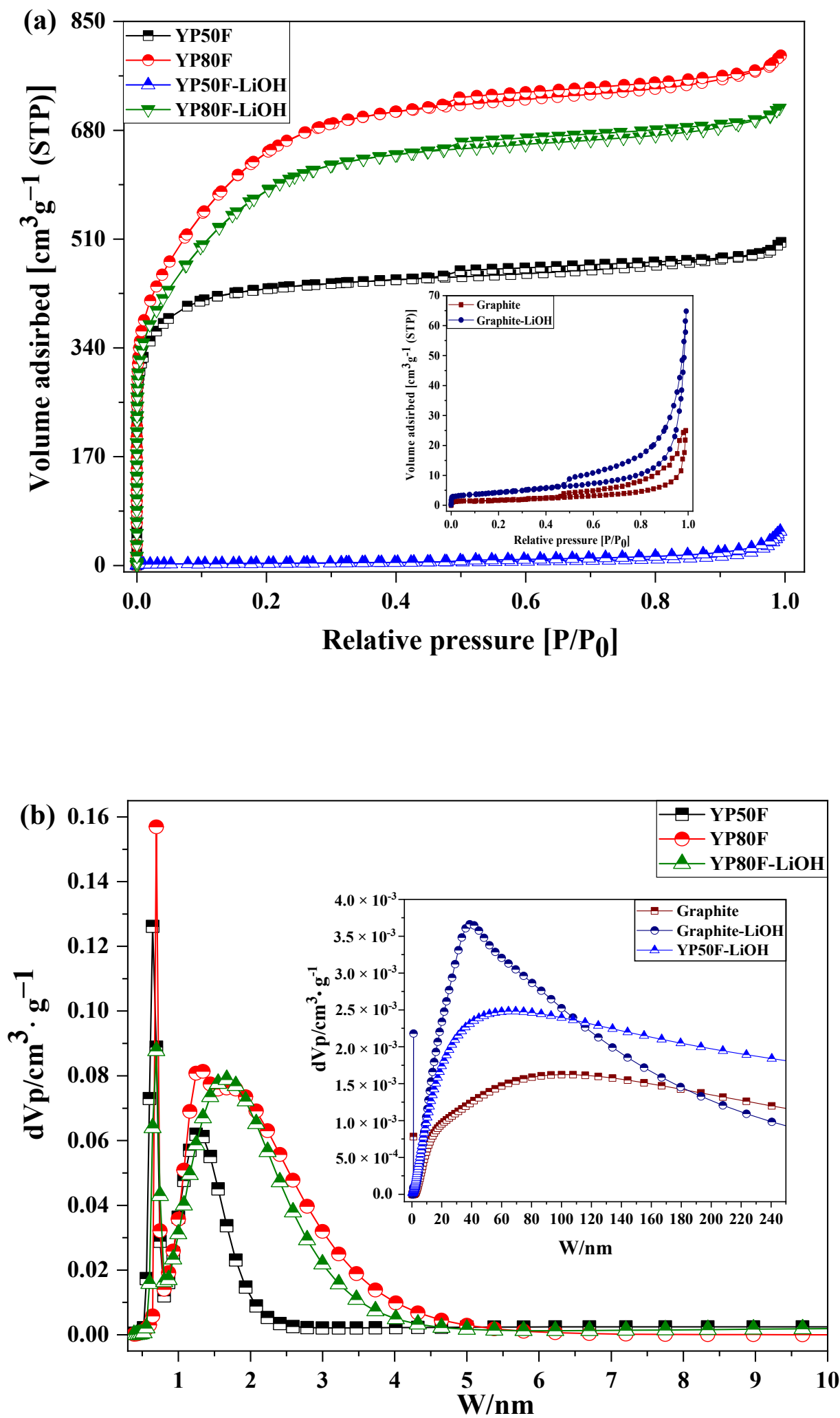

Figure 6. Cont. 

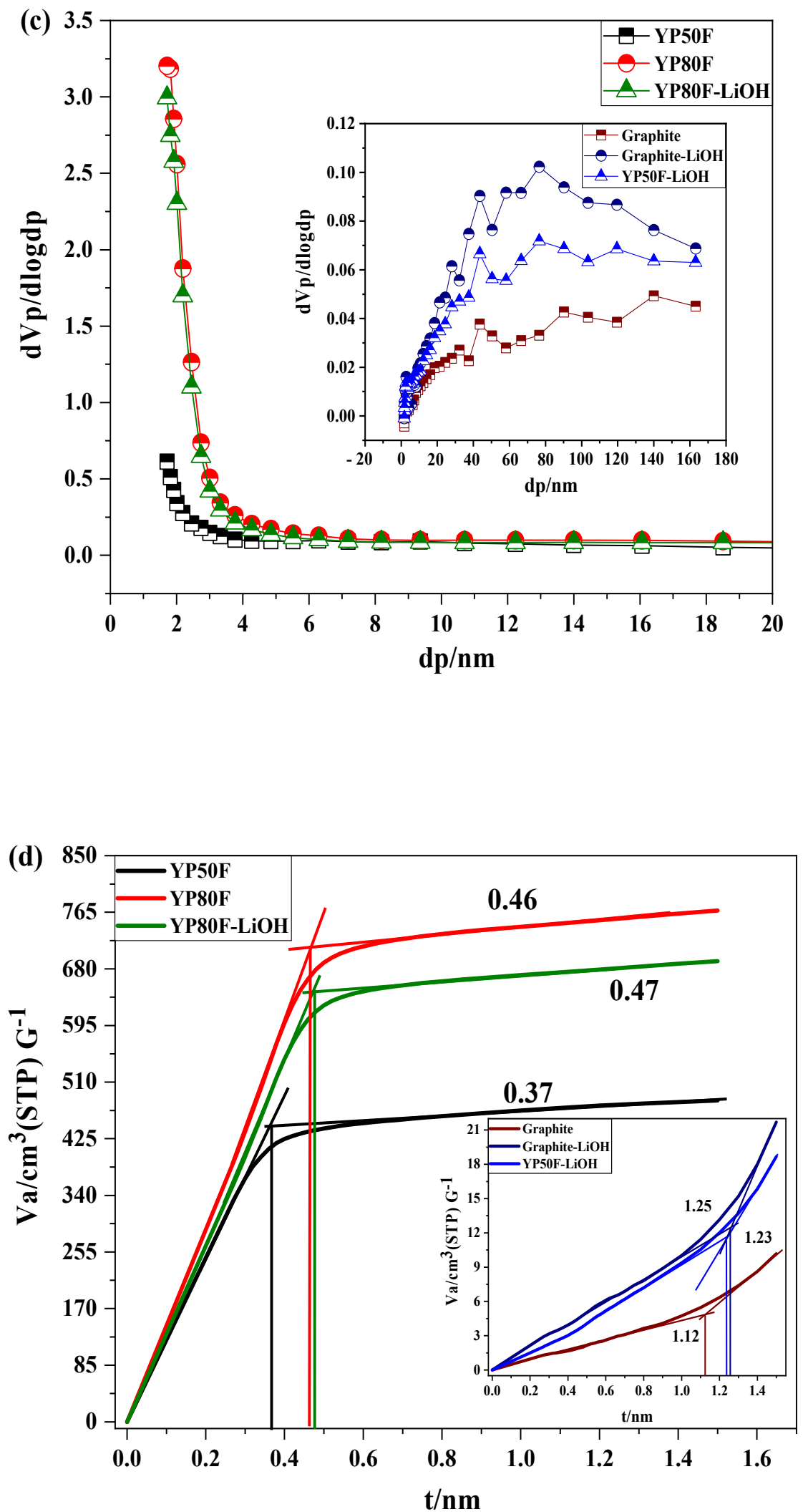

Figure 6. (a) Nitrogen adsorption-desorption isotherms, (b) NLDFT/GCMC Pore size distribution analysis, (c) BJH plot and (d) T-curve of graphite, YP50F, YP80F and LiOH-treated carbon materials. 
Table 2. Nitrogen adsorption-desorption isotherms of bare graphite, YP50F, YP80F and LiOH-treated samples.

\begin{tabular}{|c|c|c|c|c|c|c|}
\hline \multicolumn{7}{|c|}{ BET Analysis } \\
\hline Samples & \multicolumn{2}{|c|}{ Surface Area $\left(\mathrm{m}^{2} / \mathrm{g}\right)$} & \multicolumn{2}{|c|}{ Total Pore Volume $\left(\mathrm{cm}^{3} / \mathrm{g}\right)$} & \multicolumn{2}{|c|}{ Mean Pore Diameter (nm) } \\
\hline Graphite & \multicolumn{2}{|c|}{6.29} & \multicolumn{2}{|c|}{0.042} & \multicolumn{2}{|c|}{26.6} \\
\hline YP50F & \multicolumn{2}{|c|}{1676.1} & \multicolumn{2}{|c|}{0.776} & \multicolumn{2}{|c|}{1.9} \\
\hline YP80F & \multicolumn{2}{|c|}{2374.8} & \multicolumn{2}{|c|}{1.227} & \multicolumn{2}{|c|}{2.1} \\
\hline Graphite-LiOH & \multicolumn{2}{|c|}{15.2} & \multicolumn{2}{|c|}{0.094} & \multicolumn{2}{|c|}{24.6} \\
\hline YP50F-LiOH & \multicolumn{2}{|c|}{11.7} & \multicolumn{2}{|c|}{0.074} & \multicolumn{2}{|c|}{25.3} \\
\hline YP80F-LiOH & \multicolumn{2}{|c|}{2155.7} & \multicolumn{2}{|c|}{1.104} & \multicolumn{2}{|c|}{2.0} \\
\hline \multicolumn{7}{|c|}{ BJH Analysis } \\
\hline Samples & $\begin{array}{l}\text { Mesopore Pore } \\
\text { Diameter (nm) }\end{array}$ & $\begin{array}{c}\text { Micropore } \\
\text { Surface Area } \\
\left(\mathrm{m}^{2} / \mathrm{g}\right)\end{array}$ & $\begin{array}{c}\text { Mesopore } \\
\text { Surface Area } \\
\left(\mathrm{m}^{2} / \mathrm{g}\right)\end{array}$ & $\begin{array}{l}\text { Micropore } \\
\text { Volume } \\
\left(\mathrm{cm}^{3} / \mathrm{g}\right)\end{array}$ & $\begin{array}{l}\text { Mesopore } \\
\text { Volume } \\
\left(\mathrm{cm}^{3} / \mathrm{g}\right)\end{array}$ & $\begin{array}{c}\text { Micropore Vol. } \\
\text { Percent (\%) }\end{array}$ \\
\hline Graphite & 140.0 & -0.38 & 6.7 & 0.002 & 0.040 & 4 \\
\hline YP50F & 1.7 & 1471.35 & 204.8 & 0.586 & 0.191 & 75 \\
\hline YP80F & 1.7 & 1345.30 & 1029.5 & 0.571 & 0.656 & 47 \\
\hline Graphite-LiOH & 76.49 & 0.11 & 15.11 & 0.004 & 0.090 & 4 \\
\hline YP50F-LiOH & 76.5 & -3.28 & 15.0 & 0.003 & 0.072 & 3 \\
\hline YP80F-LiOH & 1.7 & 1238.64 & 917.1 & 0.526 & 0.578 & 48 \\
\hline \multicolumn{7}{|c|}{ T-Plot } \\
\hline Samples & $\begin{array}{l}\text { Total Surface } \\
\text { Area }\left(\mathrm{m}^{2} / \mathrm{g}\right)\end{array}$ & $\begin{array}{c}\text { Micropore } \\
\text { Surface Area } \\
\left(\mathrm{m}^{2} / \mathrm{g}\right)\end{array}$ & $\begin{array}{c}\text { External } \\
\text { Surface }\left(\mathrm{m}^{2} / \mathrm{g}\right)\end{array}$ & $\begin{array}{l}\text { Micropore } \\
\text { Volume } \\
\left(\mathrm{cm}^{3} / \mathrm{g}\right)\end{array}$ & $\begin{array}{l}\text { Mesopore } \\
\text { Volume } \\
\left(\mathrm{cm}^{3} / \mathrm{g}\right)\end{array}$ & $\begin{array}{c}\text { Micropore Vol. } \\
\text { Percent (\%) }\end{array}$ \\
\hline Graphite & 7.40 & 2.44 & 23.96 & -0.021 & - & \\
\hline YP50F & 1898.4 & 1639.4 & 36.7 & 0.693 & 0.084 & 89 \\
\hline YP80F & 2226.9 & 2304.4 & 70.4 & 1.084 & 0.100 & 88 \\
\hline Graphite-LiOH & 1.665 & 2.30 & 21.283 & 0.023 & - & \\
\hline YP50F-LiOH & 43.5 & 11.59 & 11.61 & 0.037 & 0.111 & 50 \\
\hline YP80F-LiOH & 1063.2 & 1094.1 & 46.0 & 0.511 & 0.143 & 84 \\
\hline
\end{tabular}

Table 3. The area, specific capacitance, energy density and power density calculation of each electrode from CV test.

\begin{tabular}{|c|c|c|c|c|c|c|}
\hline № & Sample & $\begin{array}{l}\text { Current } \\
\text { Collector }\end{array}$ & $\begin{array}{c}\text { Area of } \\
\text { Integration }\end{array}$ & $\begin{array}{l}\text { Specific Capacitance } \\
\text { (Cp) (F/g) }\end{array}$ & $\begin{array}{l}\text { Energy Density } \\
\text { (Wh/kg) }\end{array}$ & $\begin{array}{l}\text { Power Density } \\
\quad(\mathrm{kW} / \mathrm{kg})\end{array}$ \\
\hline \multirow{2}{*}{1} & \multirow{2}{*}{ Li-YP80F } & Cu foil & $9.828 \times 10^{-4}$ & $1.196 \times 10^{-4}$ & 14.95 & 66.44 \\
\hline & & Ni foil & $3.918 \times 10^{-4}$ & $2.118 \times 10^{-5}$ & 2.65 & 13.81 \\
\hline \multirow{2}{*}{2} & \multirow{2}{*}{ Li-YP50F } & $\mathrm{Cu}$ foil & $7.601 \times 10^{-4}$ & $1.169 \times 10^{-4}$ & 14.61 & 59.77 \\
\hline & & Ni foil & $2.21 \times 10^{-4}$ & $1.21 \times 10^{-5}$ & 1.51 & 7.26 \\
\hline \multirow{2}{*}{3} & \multirow{2}{*}{ Li-Graphite } & $\mathrm{Cu}$ foil & $6.559 \times 10^{-4}$ & $1.17 \times 10^{-4}$ & 14.62 & 57.83 \\
\hline & & $\mathrm{Ni}$ foil & $2.158 \times 10^{-4}$ & $1.192 \times 10^{-5}$ & 1.49 & 6.79 \\
\hline
\end{tabular}

The wettability of the $\mathrm{LiOH}$-treated carbon materials was tested by gravimetric methods using water and 5\% $\mathrm{KOH}$ (Figure 7). The measurement-based of determining how much amount of solvent (water, $5 \% \mathrm{KOH}$ ) absorbed in the working electrode which using a LiOH-treated carbon material and pure carbon material. The results of the wettability properties of all samples are summarized in Bit-graph. According from the summarized 
result, $\mathrm{LiOH}$-treated sample has high wettability properties, due to the acidic groups of the surface which can affect the impregnation of the electrolyte. The main purpose of the study was to change the surface of the carbon material by the method of functional groups with hydrophilic and hydrophobic properties, depending on the type of electrolyte applied. The results of the experiments confirm that the surface of the carbon material has been successfully modified to a hydrophilic quality using $\mathrm{LiOH}$-oxidizing agents.

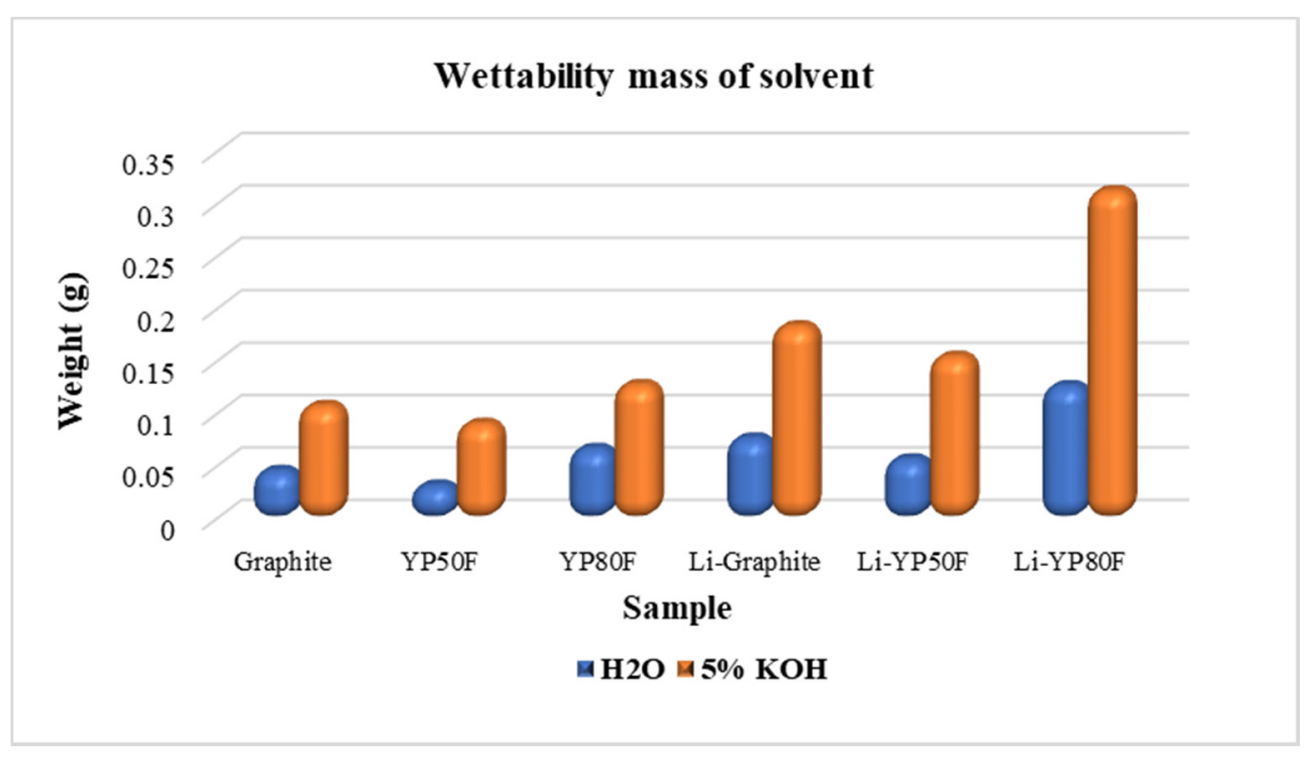

Figure 7. Bit-graph. The wettability of the carbon samples.

Figure 8 expresses the Raman spectra of the LiOH-treated graphite, YP50F and YP80F samples. Raman spectroscopy is the chemical-analysis method which can analyze the chemical structure phase and molecular interaction of matter. The principle of Raman spectroscopy is a light-scattering technique, where the light interact to the molecule bond and the result provides the information of carbon material ( $D$ and G-band). The assignment of the D and G peaks is straightforward in the "molecular" picture of carbon materials. The Raman spectrum of LiOH-YP50F and LiOH-YP80F is dominated by two prominent features. The $\mathrm{G}$ band near 1597 and $1591 \mathrm{~cm}^{-1}$ is due to the degenerate zone-center (G) optical phonon mode with $\mathrm{E}_{2 \mathrm{~g}}$ symmetry, which is found in most graphitic materials. The most important is the D band near 1332 and $1338 \mathrm{~cm}^{-1}$ due to a one-phonon scattering involving a phonon near the K point and scattering due to defects [27].

Two broad peaks at 2657, 2662, 2914 and $2904 \mathrm{~cm}^{-1}$ observed in the spectrum of $\mathrm{LiOH}$ was also detected in the Raman spectrum of LiOH-treated YP50F and YP80F. These two peaks are assigned to the asymmetric $\left(\mathrm{B}_{\mathrm{g}}\right)$ and symmetric $\left(\mathrm{A}_{\mathrm{g}}\right)$ stretches [28]. The five

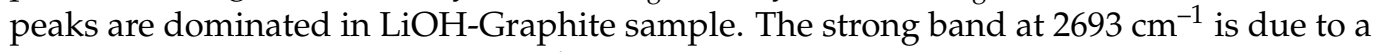
two-phonon scattering involving $A_{1}^{\prime}$ phonons near the $\mathrm{K}$ point and is called the $2 \mathrm{D}$ band. The $2 \mathrm{D}$ band is usually stronger than the $\mathrm{G}^{*}$ and $\mathrm{G}^{\prime}$ band although it is due to a two-phonon scattering process. The triple resonance process, where the electron and the hole scatter simultaneously, can also explain the two-phonon scattering. The characteristic peak of $\mathrm{LiOH}$ not obtained in $\mathrm{LiOH}-\mathrm{Graphite}$ sample, due to the peak intensity of each components.

\subsection{Electrochemical Test}

The high surface area of YP50F, YP80F activated carbon and graphite was modified with $\mathrm{LiOH}-$ oxidizing agent and heat treatment $\left(600^{\circ} \mathrm{C}\right)$. HSAC materials with a microporous structure can be synthesized by $(\mathrm{LiOH})$ oxidizing agent treatment for the high surface area of activated carbon under the high temperature. In addition, after the activated carbon reacting with oxidizing agents, the number of basic functional groups decreases, 
the number of hydrophilic groups increases, or the hydrophilicity of the activated carbon surface improves, which can improve the long-term reliability of the cell.

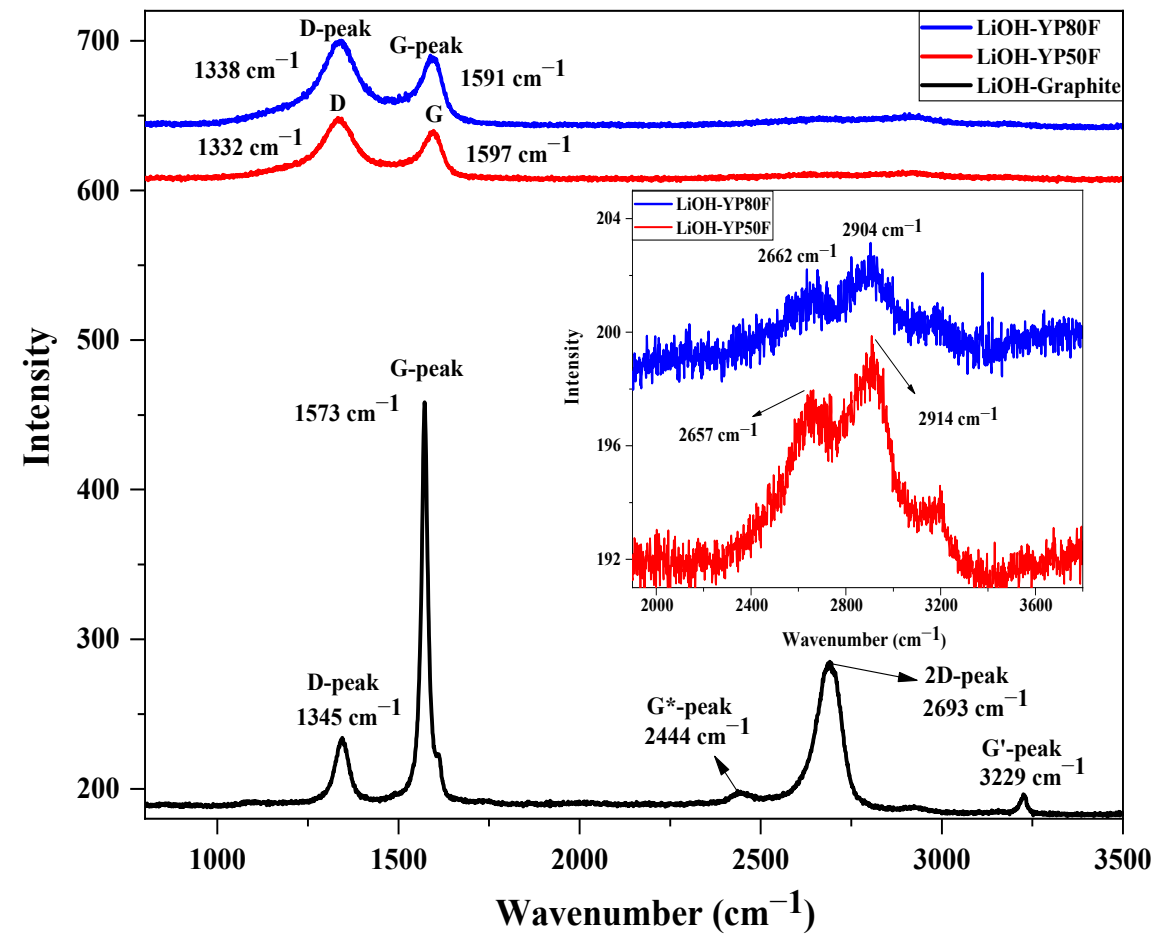

Figure 8. Raman spectra of the LiOH-Graphite, LiOH-YP50F and LiOH-YP80F sample (G*-twophonon processes).

The Li-HSAC samples were used for the working electrode by following a Doctor blade" method. The electrochemical performance and work-function of the electrode were analyzed by a cyclic voltammetry (CV) and chronoamperometry (CA) technique. The $\mathrm{CA}$ technique is useful that Potentiastat transient measurement is a favorable method to analyze the capacity-rate curve of the working electrode [29]. The CV tests were carried out in a three-electrode system. In this performance, $\mathrm{Cu}$-foil and Ni-foil was used as a current-collector and the high ionic conductivity of the $\mathrm{KOH}$ basic solutions was used for the electrolyte [30]. $\mathrm{KOH}$ is a basic electrolytes and it has been the most extensively used because of its high ionic conductivity and it can support the cyclic stability of the working electrode.

The CV test was run for 10 and 100-cycles with $100 \mathrm{mV} / \mathrm{s}$ scan rate. The CV graph and current value were different in each sample according to the working electrode. The CV result of Li-YP80F is shown in Figure 9a,b. The anodic and cathodic peak current value and peak segregation of Li-YP80F were better than those of the other two samples, due to the micropore-size and physical properties of the sample. The oxidation peak current value appeared at $0.0055 \mathrm{~mA} / \mathrm{cm}^{2}$ current density and the reduction peak value at $-0.0014 \mathrm{~mA} / \mathrm{cm}^{2}$, when the Li-YP80F sample used to the $\mathrm{Cu}$-foil surface. The redox peaks appeared at $0.0025 \mathrm{~mA} / \mathrm{cm}^{2}$ and $-0.0009 \mathrm{~mA} / \mathrm{cm}^{2}$, in the case of using a Nickel foil, as shown in Figure 9b.

As shown in Figure 9c, the CV curve had one sharp peak in the oxidation state. The oxidation peak appeared at $0.0035 \mathrm{~mA} / \mathrm{cm}^{2}$ and the reduction-peak at the $0.00042 \mathrm{~mA} / \mathrm{cm}^{2}$ regions. When the Li-YP50F covered on the nickel foil, the redox peaks appeared at $0.00231 \mathrm{~mA} / \mathrm{cm}^{2}$ and $-0.00051 \mathrm{~mA} / \mathrm{cm}^{2}$ current density regions, as shown in Figure $9 \mathrm{~d}$. For the Li-graphite, the current density of the oxidation peak appeared at $0.0053 \mathrm{~mA} / \mathrm{cm}^{2}$ and the reduction peak at $\left(-0.00045 \mathrm{~mA} / \mathrm{cm}^{2}\right)$, as shown in Figure $9 \mathrm{e}$. In the case of Ligraphite coated on the nickel foil surface, the oxidation peak appeared at $0.0013 \mathrm{~mA} / \mathrm{cm}^{2}$ and reduction peak appeared at $-0.00083 \mathrm{~mA} / \mathrm{cm}^{2}$ region, as shown in Figure $9 \mathrm{f}$. 

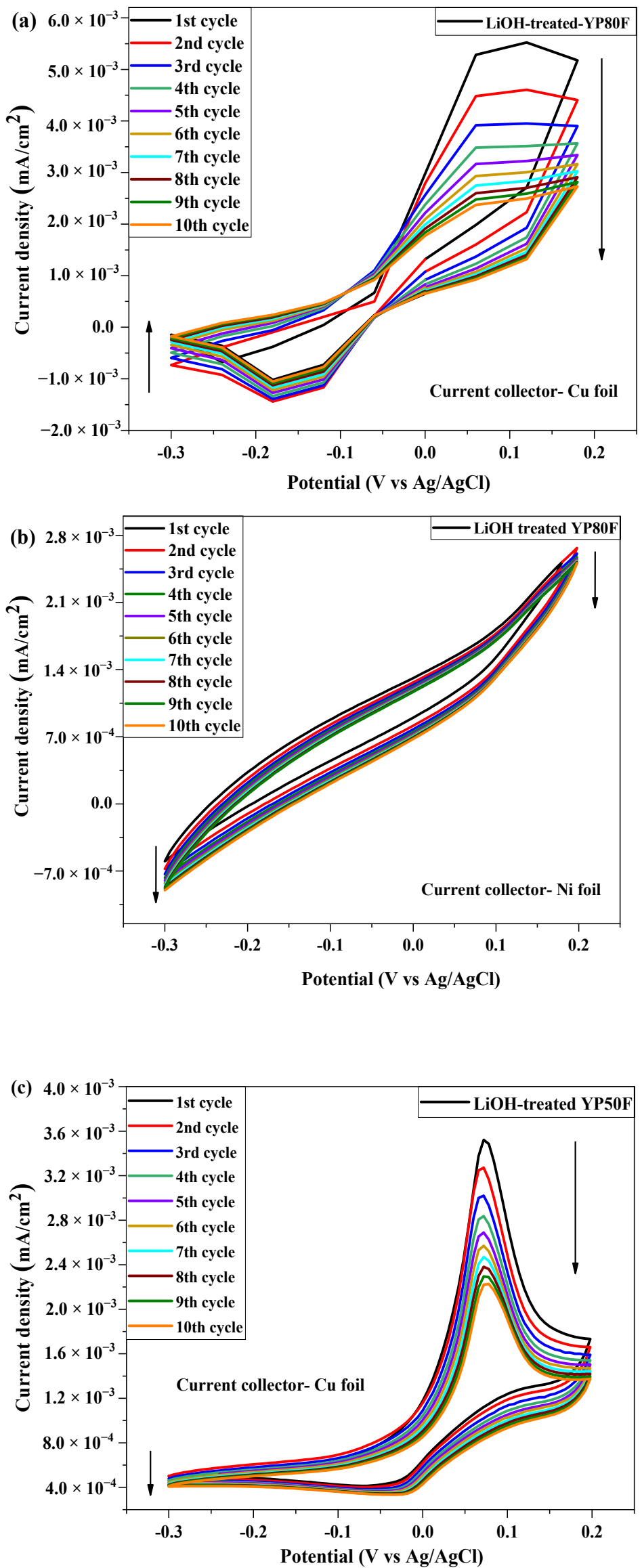

Figure 9. Cont. 

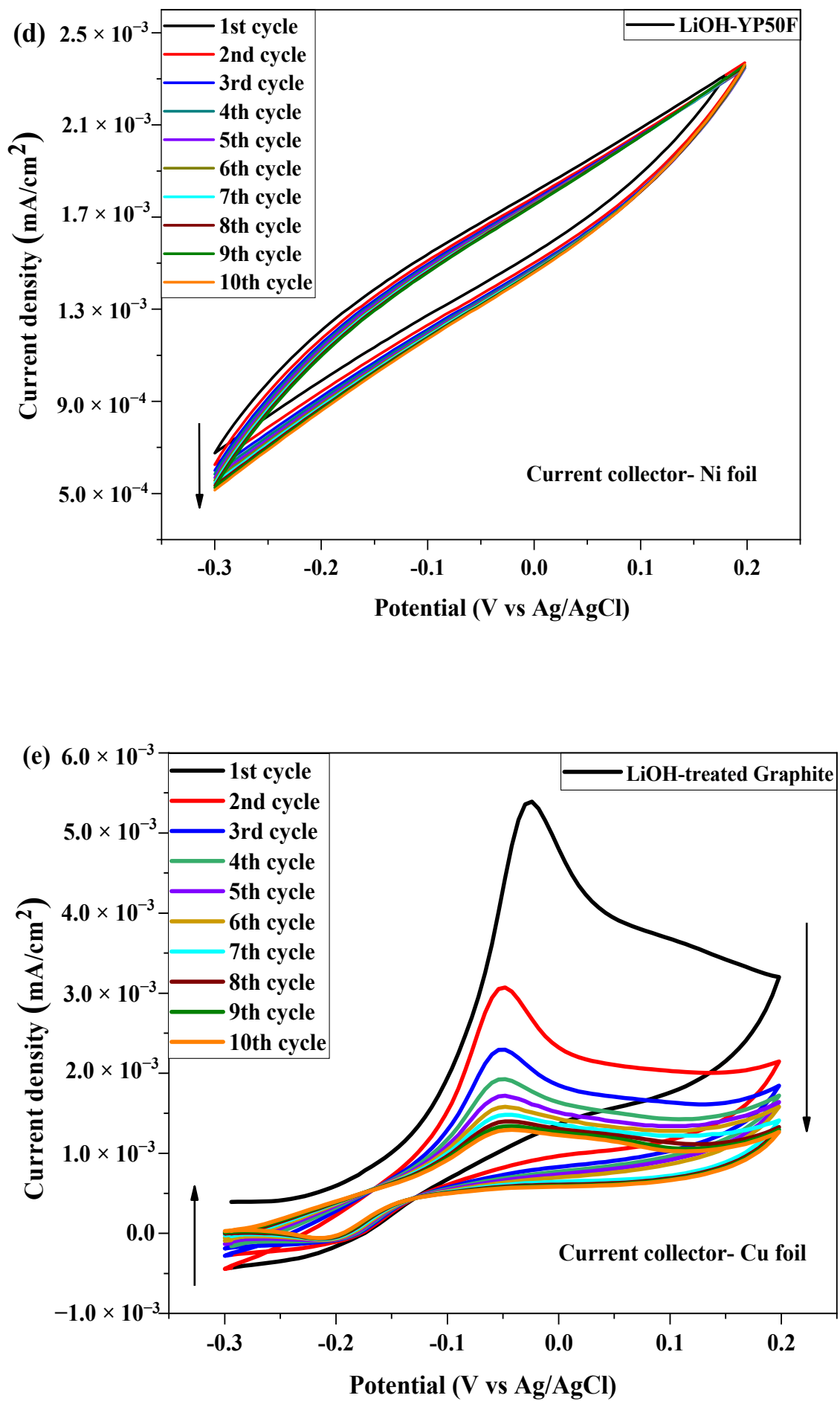

Figure 9. Cont. 


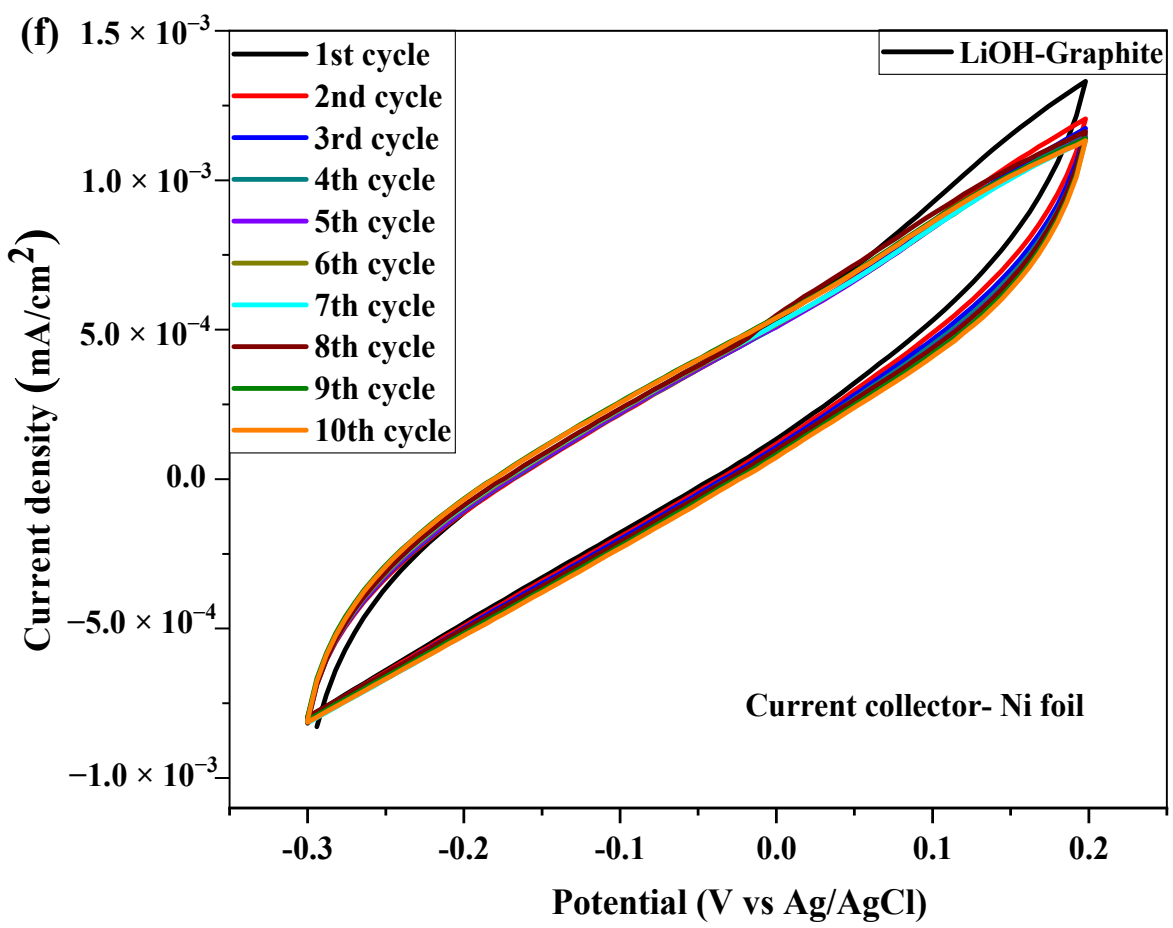

Figure 9. Cyclic voltammetry (CV) test of (current collector-Cu foil and $\mathrm{Ni}$ foil and $5 \% \mathrm{KOH}$ electrolyte) under 10 cycles (a) LiOH-YP80F with Cu-foil; (b) LiOH-YP80F with Ni-foil; (c) LiOHYP50F with Cu-foil; (d) LiOH-YP80F with Ni-foil; (e) LiOH-Graphite with Cu-foil; (f) LiOH-Graphite with Ni-foil.

The electrochemical properties of the Li-HSAC sample depend on three main factors: the functional group, surface area, and pore size distribution. The interfacial area, the ion-transfer between the electrode surface and the electrolyte depend on the pore size and the surface area. The analysis results revealed that the specific surface area and pore size were higher for Li-YP80F than for the other two samples, which strongly improved the electrochemical performance.

The use of Li-YP80F, a material with a high surface area, as a working electrode allows for more charge exchange and, on the other hand, allows more electrons to accumulate over a given period of time and conduct more current. The charge exchange happens at a fixed rate per unit area at the surface of the electrode. Also, the numerous acidic functional groups of Li-YP80F enabled it to maintain the permeability of the electrolyte and reduce the resistivity between the electrolyte and working electrode. In the $C V$ graph, the peak separation is dependent on the electron transfer kinetics and conductivity of the base aqueous electrolyte. In addition, the high conductivity of the as-prepared $\mathrm{KOH}$ electrolyte influenced the performance of the working electrode [31]. Specifically, the electron transfer of the working electrode was high when the working electrode was dipped in electrolyte. The conductivity of the base-electrolyte is conditional-on the smaller ionic hydrated-radius and rapid-motility of $\mathrm{OH}^{-}$[32-34]. In addition, the $C V$ graph profile was changed due to the carbon material of the base substrate, for example, the oxidation peak-current state changed from $0.0055 \mathrm{~mA} / \mathrm{cm}^{2}$ to the current density state to $0.0035 \mathrm{~mA} / \mathrm{cm}^{2}$. In addition, the $\mathrm{Cu}$ plate collector has a conductivity of $0.6 \mathrm{~S} / \mathrm{cm}$ and it can support the activity of the base sample. The specific capacitance, area of the integration, energy density $(\mathrm{Wh} / \mathrm{kg})$ at given powder density $(\mathrm{kW} / \mathrm{kg})$ are important factors which define the performance of the working electrode. Aforementioned mentioned all factors were calculated by following the 
below Equations (1)-(7). All calculated results are summarized in Table 3. The calculation of specific capacitance needs to summarize some units, such as charge, capacitance.

$$
\begin{gathered}
\text { charge }=\frac{\text { integrated area of } C V}{2 x \text { Scan rate }} \\
\text { capacitance }=\frac{\text { charge }}{\text { potential window }} \\
\text { specific capacitance }=\frac{\text { capacitance }}{\text { mass of active material }} \\
\text { Combined equation was the } \mathrm{Cp}=\frac{A}{2 m k(V 2-V 1)}
\end{gathered}
$$

where $\mathrm{Cp}$ is the specific capacitance in $\mathrm{F} / \mathrm{g}$. $A$ is the area inside the $C V$ curve having units $\mathrm{AV}, m$ is the mass of active material, $k$ is the scan rate of $C V$ in volts per second and $\left(V_{2}-V_{1}\right)$ is the potential window of $C V$.

The calculation of energy density $(\mathrm{Wh} / \mathrm{kg})$ and powder density $(\mathrm{W} / \mathrm{g})$.

$$
\begin{gathered}
C=\frac{i \times t}{m \times \Delta U} \\
d E\left(\frac{W h}{k g}\right)=0.5 \times C \times(\Delta U)^{2} \\
d P\left(\frac{k W}{k g}\right)=\left(\frac{d E}{1000}\right) \div\left(\frac{t}{3600}\right)=3.6 \times \frac{d E}{t}
\end{gathered}
$$

where $C$ is the capacitance, $\Delta U$ is potential window, $t$ is discharge time, the factor 3.6 is used as correcting the unit form gram and second into kilogram and hour.

The electrochemical stability of cathode materials was tested by 100 recycling tests. The peak-to-peak separation and high redox peaks appeared in the $\mathrm{Cu}$-foil used three electrode system. After 100 recycling tests, peak current drop decreased the peak profile became stable. The electrochemical stability of cathode materials was tested by 100 recycling tests, as shown in Figure 10. The Cu-current collector of the working electrode was corroded, and the surface of the electrode did not change after the electrochemical test. In the case of nickel foil, there is no corrosion process appeared and the current peak did not significantly change. The corrosion process can be happened due to the electrolyte and concentration.

Figure 11 shows the current value of the working electrode (vs. $\mathrm{Ag} / \mathrm{AgCl}$ ) according to time-condition in $5 \% \mathrm{KOH}$ electrolyte. The current of the working electrode was high in the first cycle and decreased to a certain extent after 10 cycles. The profile of Li-YP80F had a uniform structure and this result confirmed that Li-YP80F sample had more stable structure and the working performance.

Figure 12 shows the $\mathrm{CA}$ analysis result of the bare-carbon material and modified Li-HSAC. The fundamental technique of the CA is to analyze the potential and capacity of the working electrode according to time, as is done in the GCD method. The analysis revealed a high current on Li-YP80F, which confirmed that the material had a high work capacity and was suitable for the cathode electrode in a half-cell. The flat band potential of Li-YP50F, Li-YP80F and graphite was analyzed by the Mott-Schottky method. Depending on the potential of the flat strip, the material type can be defined as $n$ or p-type. As shown in Figure 13, the flat band potentials of the nanocomposite were $0.009 \mathrm{~V}, 0.074 \mathrm{~V}$ and $-0.095 \mathrm{~V}$, respectively. The Mott-Schottky slope graph shows that the Li-YP50F and Li-graphite are p-materials and the Li-YP80F is an n-type material.

Figure 14 shows a schematic illustration of the Li-HSAC surface state and electrochemical analysis. The graphite had a layered-like structure with a hexagonal arrangement of carbon atoms, which provides sufficient area for locating the oxidizing agents. The Li-YP50F and Li-YP80F materials have different porous structures, and oxidizing agents 
can accumulate in the pores. The pore structure of Li-YP80F and Li-YP50F was sufficient for electrolyte-ion conduction and distribution, due to the hydrophilic properties and the high area of material interaction. These results confirmed that the Li-YP80F electrode had high capability and electrochemical property. The structure of the oxidizing agent can improve the interfacial area of the electrolyte and working electrode surface. Furthermore, the high pore size distribution of Li-YP80F afforded it with high ion-transfer performance. These electrochemical results confirmed that oxidizing agent treatment with calcination can enhance the performance of the high surface area of carbon materials. In addition, the values of the surface functional groups were higher than the purpose of this study, which demonstrated that our $\mathrm{LiOH}$ treatment experiments provided a sufficient number of acidic functional groups on the surface of carbon materials and reduced the basic-functional groups. Depending on the ratio of the acidic and basic groups, the electrolyte impregnation on the electrode surface and interface resistance can be reduced. Furthermore, our mentioned method and characterization proved that oxidizing agent $(\mathrm{LiOH})$ treatment with a heating process can ameliorated the cathode electrode performance.
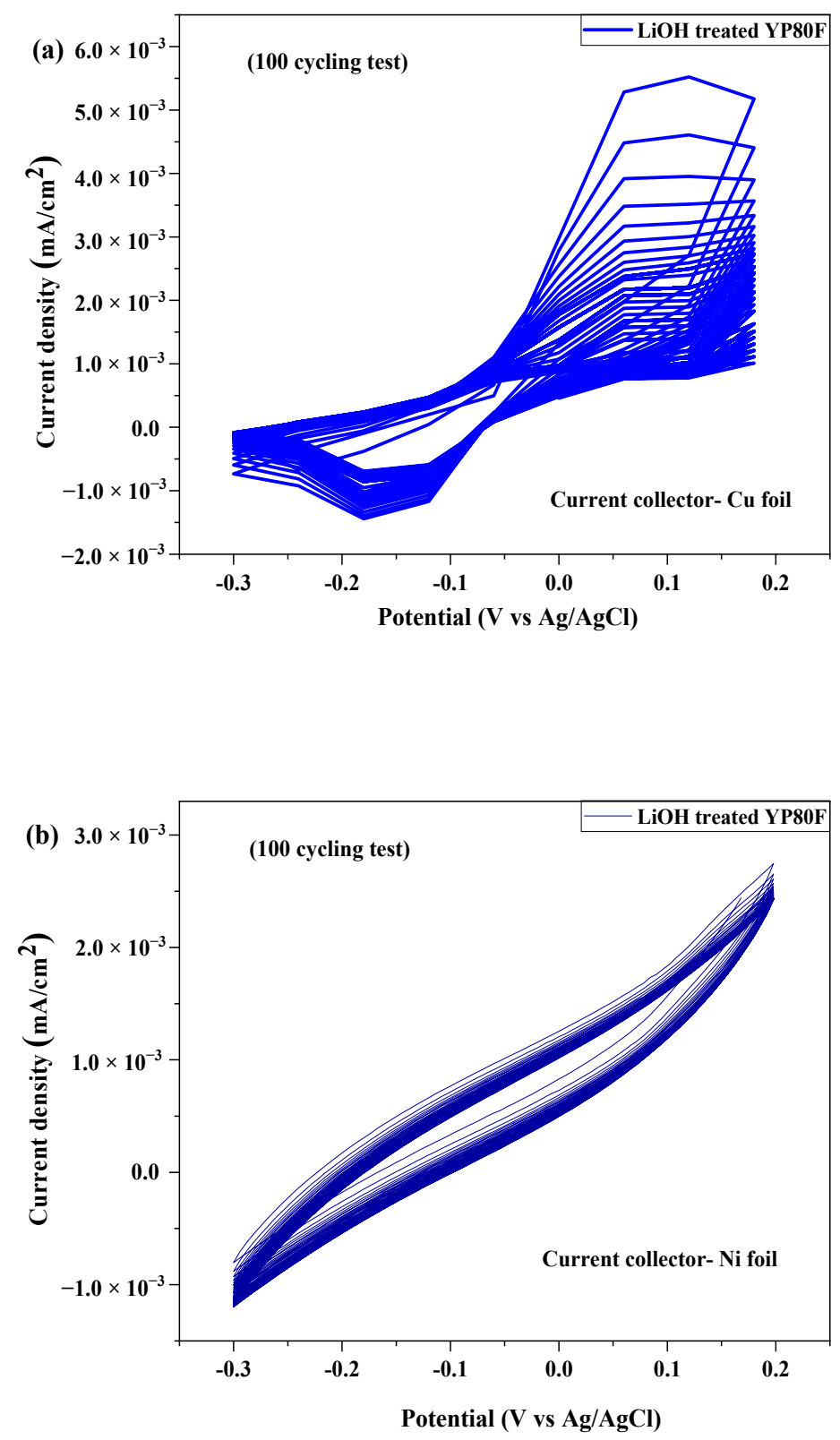

Figure 10. Cont. 

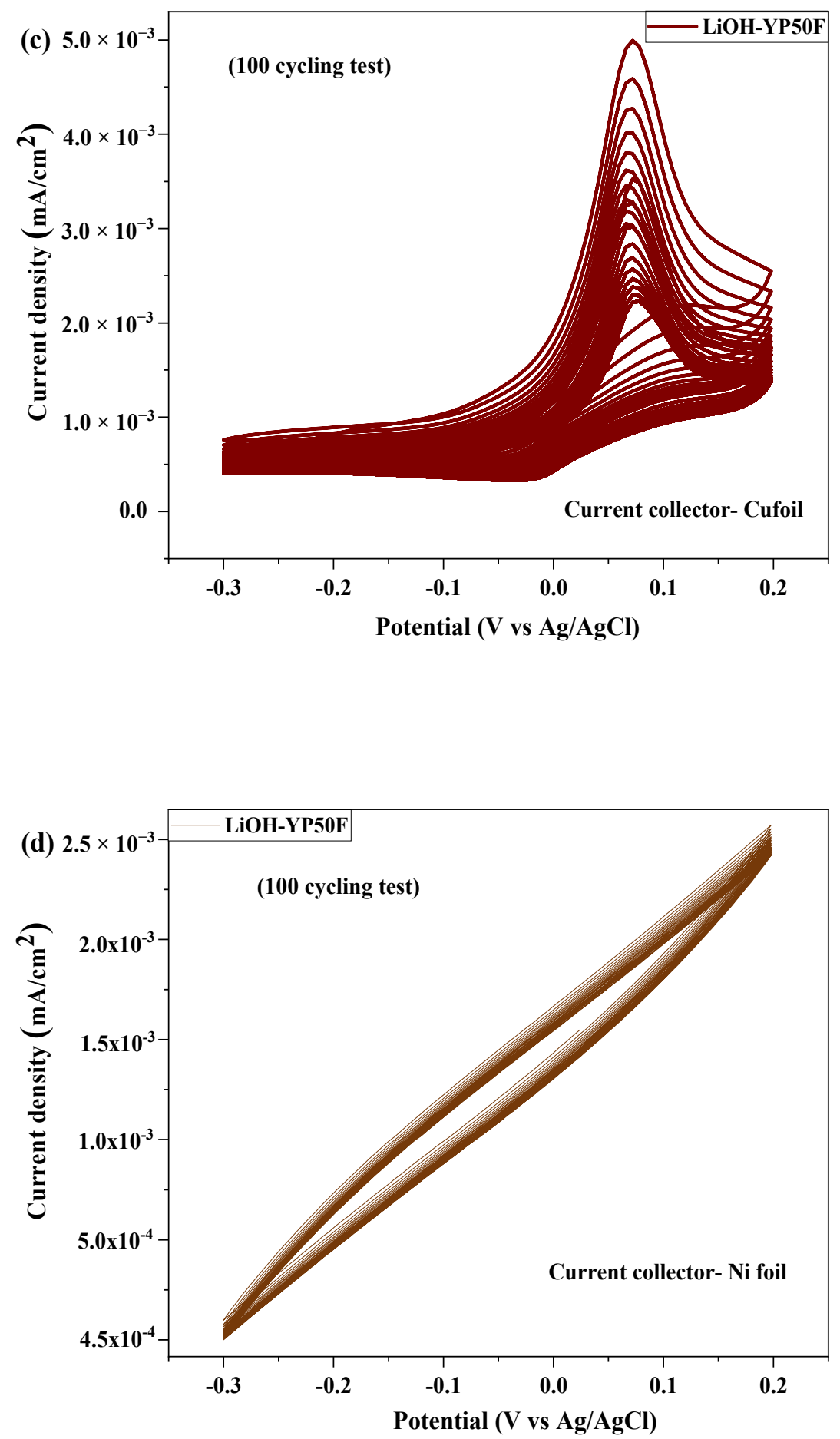

Figure 10. Cont. 

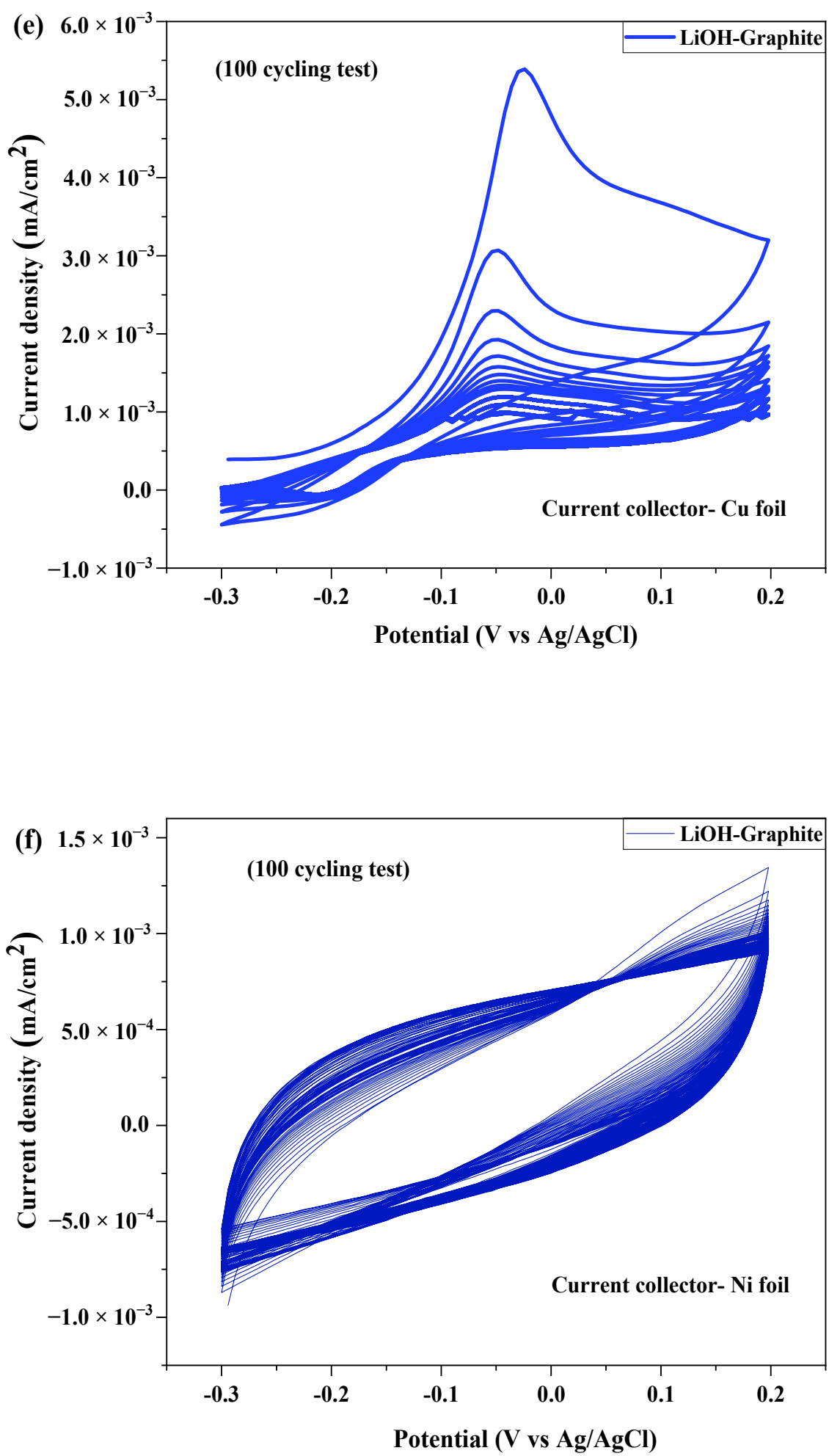

Figure 10. Cyclic voltammetry (CV) test (current collector- $\mathrm{Cu}$ foil and $\mathrm{Ni}$ foil and $5 \% \mathrm{KOH}$ electrolyte) under 100 cycles. (a) LiOH-YP80F with Cu-foil; (b) LiOH-YP80F with Ni-foil; (c) LiOH-YP50F with Cu-foil; (d) LiOH-YP80F with Ni-foil; (e) LiOH-Graphite with Cu-foil; (f) LiOH-Graphite with Ni-foil.

Recently, various activated carbon-based electrode materials have been used for electrochemical analysis, and the research has suggested the properties of surface area, pore size, and surface chemistry. These properties strongly influence the electrode capacity and charging/discharging performance used in the long-term cycle analysis [35-37]. The 
micro-sized pore and low specific surface area strongly affect the interaction site and block the ion-transmittance. In conclusion, the pore volume and surface area were significantly reduced on the HSAC after the $\mathrm{LiOH}$ treatment with the thermal process. However, the high total surface area of Li-YP80F enhanced the inter-facial site and reaction field between the electrolyte and electrode. The number of the acidic functional groups is greater than the target value, which supports the process of electrolyte ion transfer and diffusion through the micro-sized pores. The wettability condition of the electrode surface and low resistance with high charge transfer depend on the acidic functional group of the high surface area of activated carbon. These aforementioned factors combined to synergistically upgrade the electrochemical activity of the Li-HSAC nanomaterial.
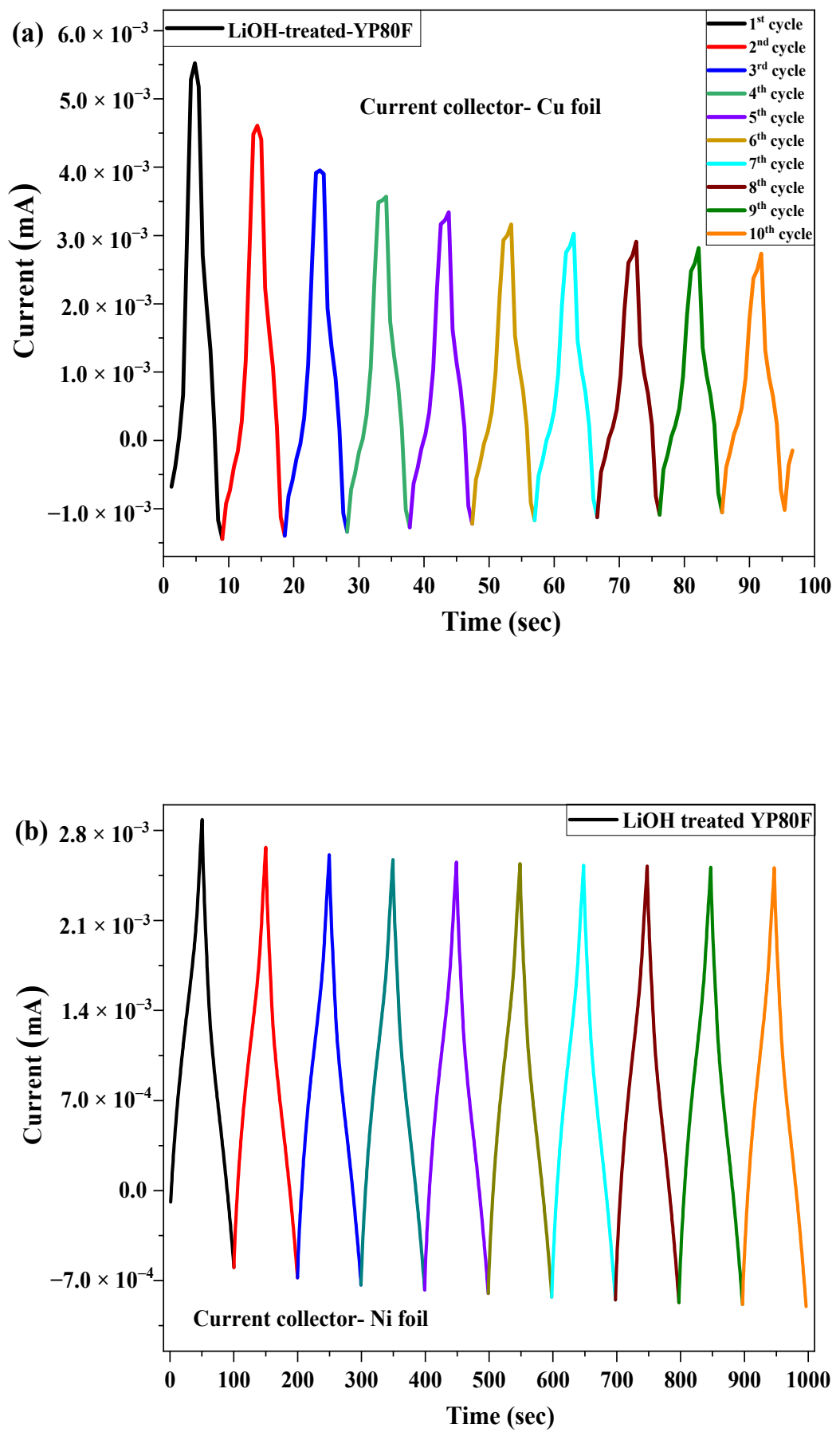

Figure 11. Cont. 

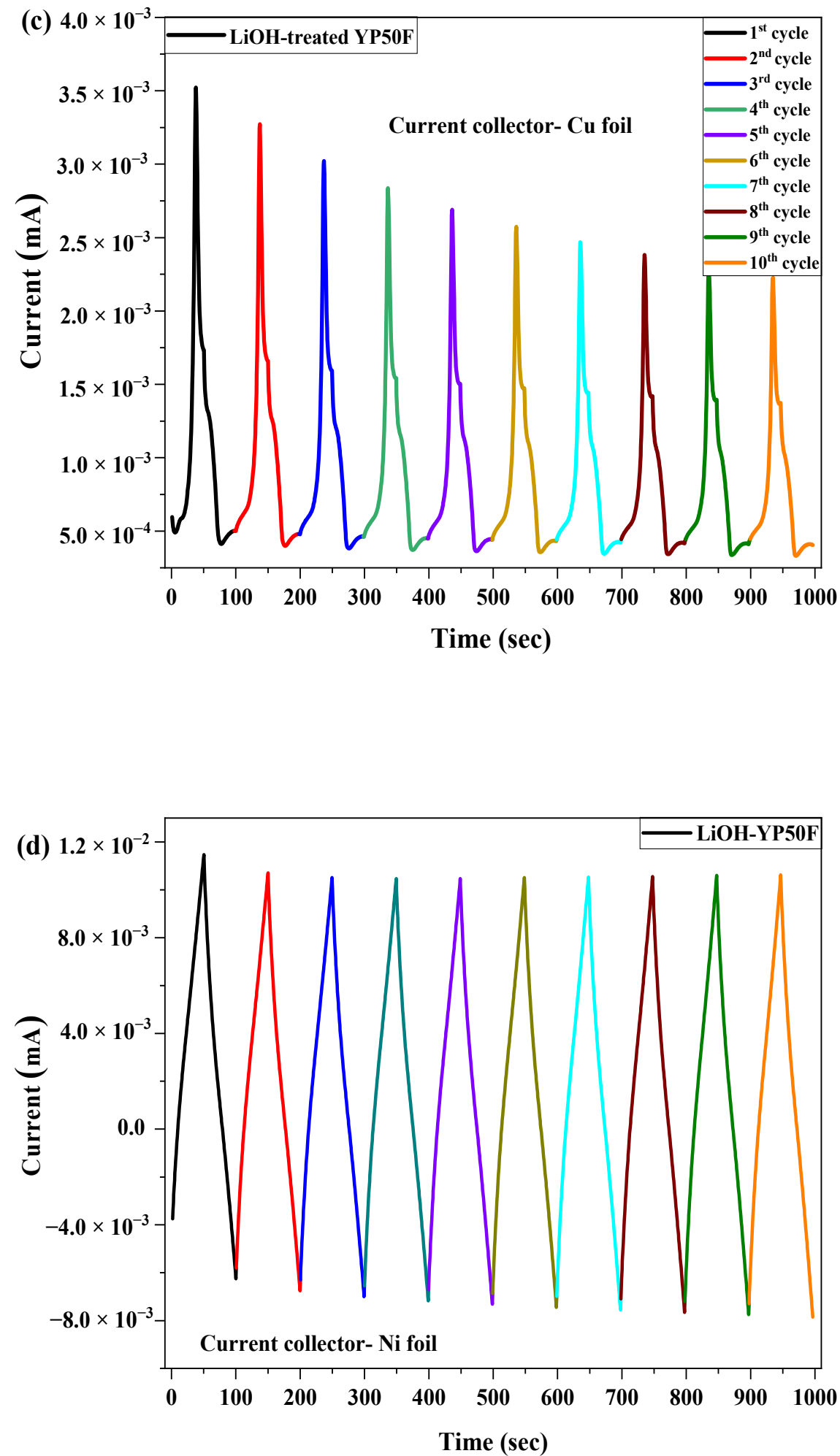

Figure 11. Cont. 

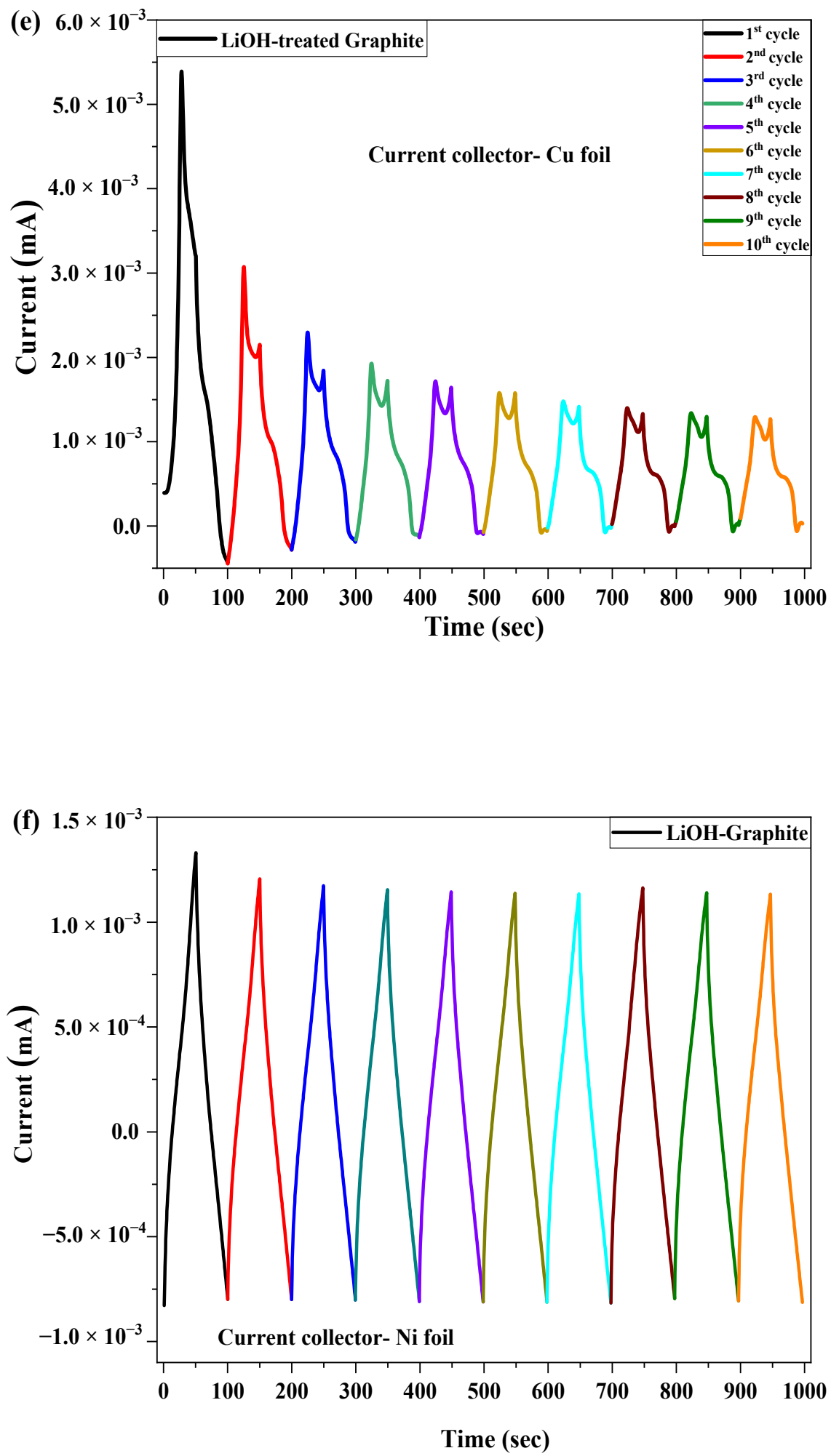

Figure 11. Stability test of LiOH-treated YP80F, YP50F and graphite (Cu-foil and Ni-foil current collector and 5\% $\mathrm{KOH}$ electrolyte). (a) LiOH-YP80F with Cu-foil; (b) LiOH-YP80F with Ni-foil; (c) LiOH-YP50F with Cu-foil; (d) LiOH-YP50F with Ni-foil; (e) LiOH-Graphite with Cu-foil; (f) LiOHGraphite with Ni-foil. 

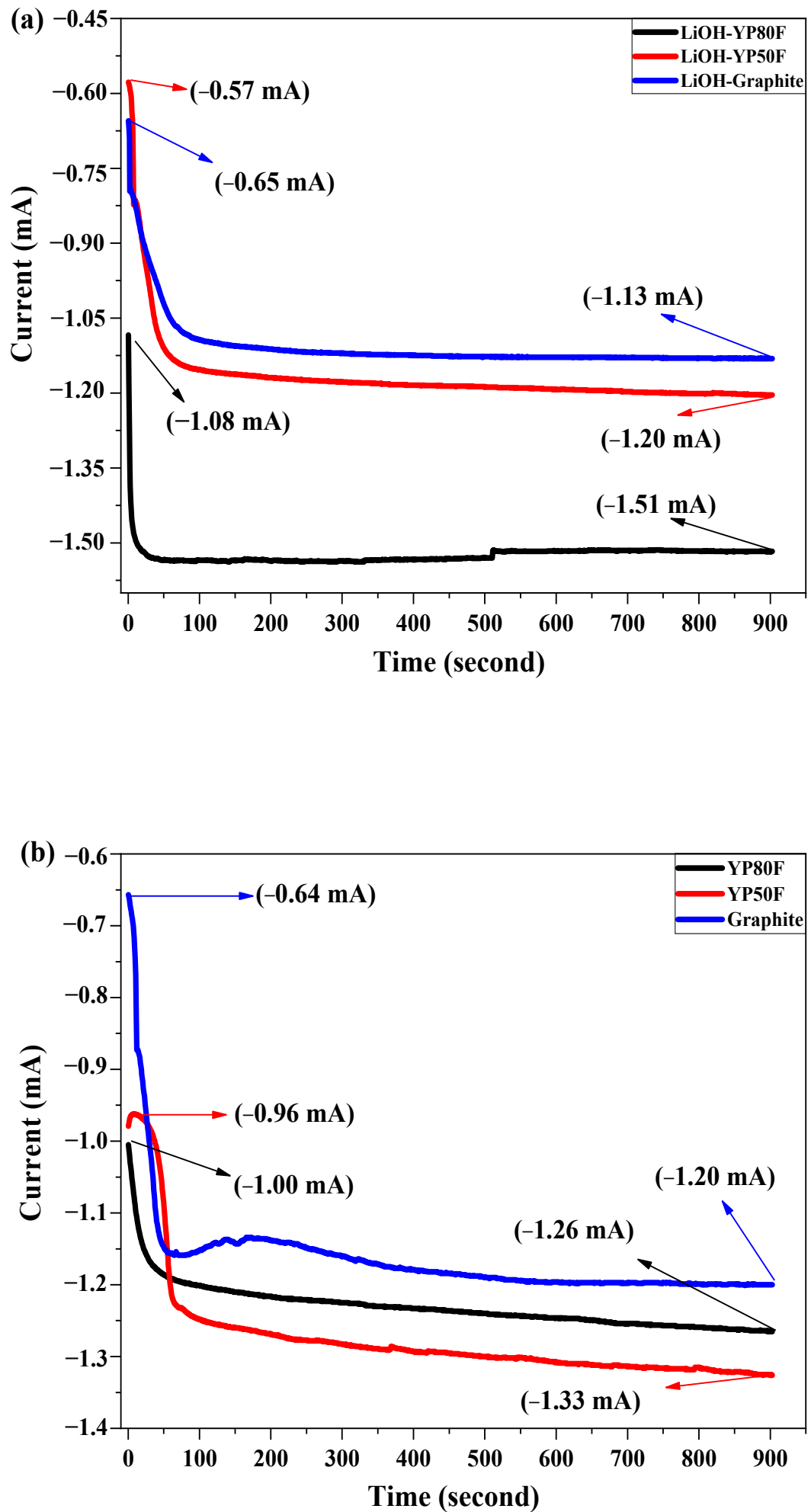

Figure 12. Chronoamperometry test of LiOH-treated YP80F, YP50F and Graphite (Cu-current collector and 5\% KOH electrolyte). (a) LiOH-treated samples; (b) pure samples. 

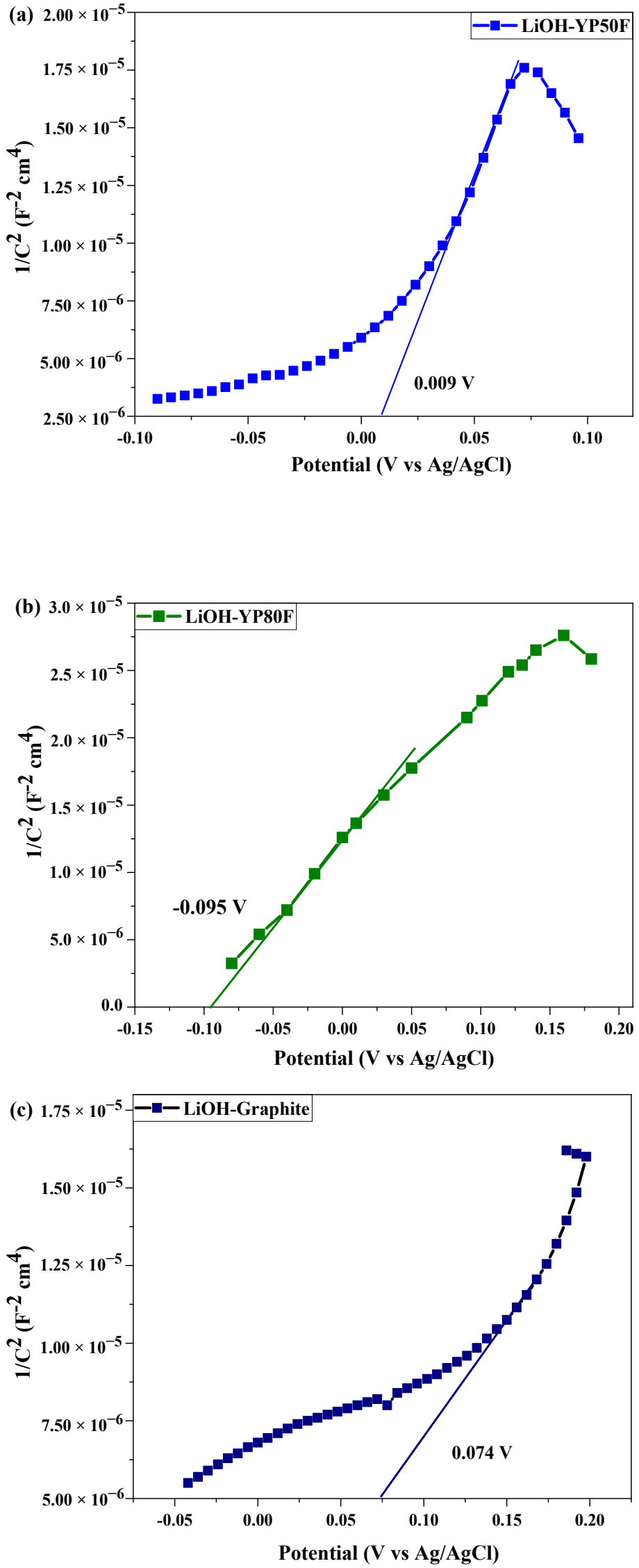

Figure 13. Mott-Schottky plot of LiOH-treated (a) YP50F, (b)YP80F, and (c) graphite (Cu-current collector and $5 \% \mathrm{KOH}$ electrolyte). 

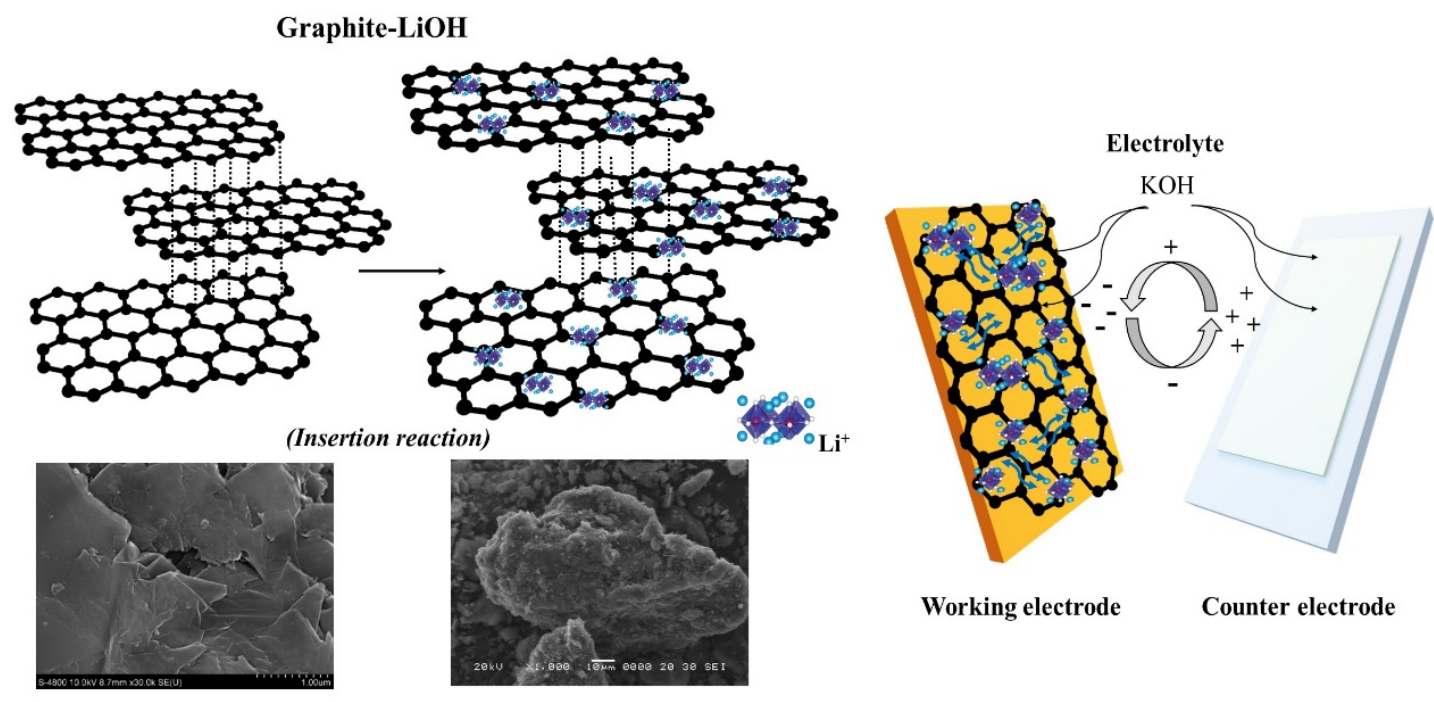

Working electrode Counter electrode
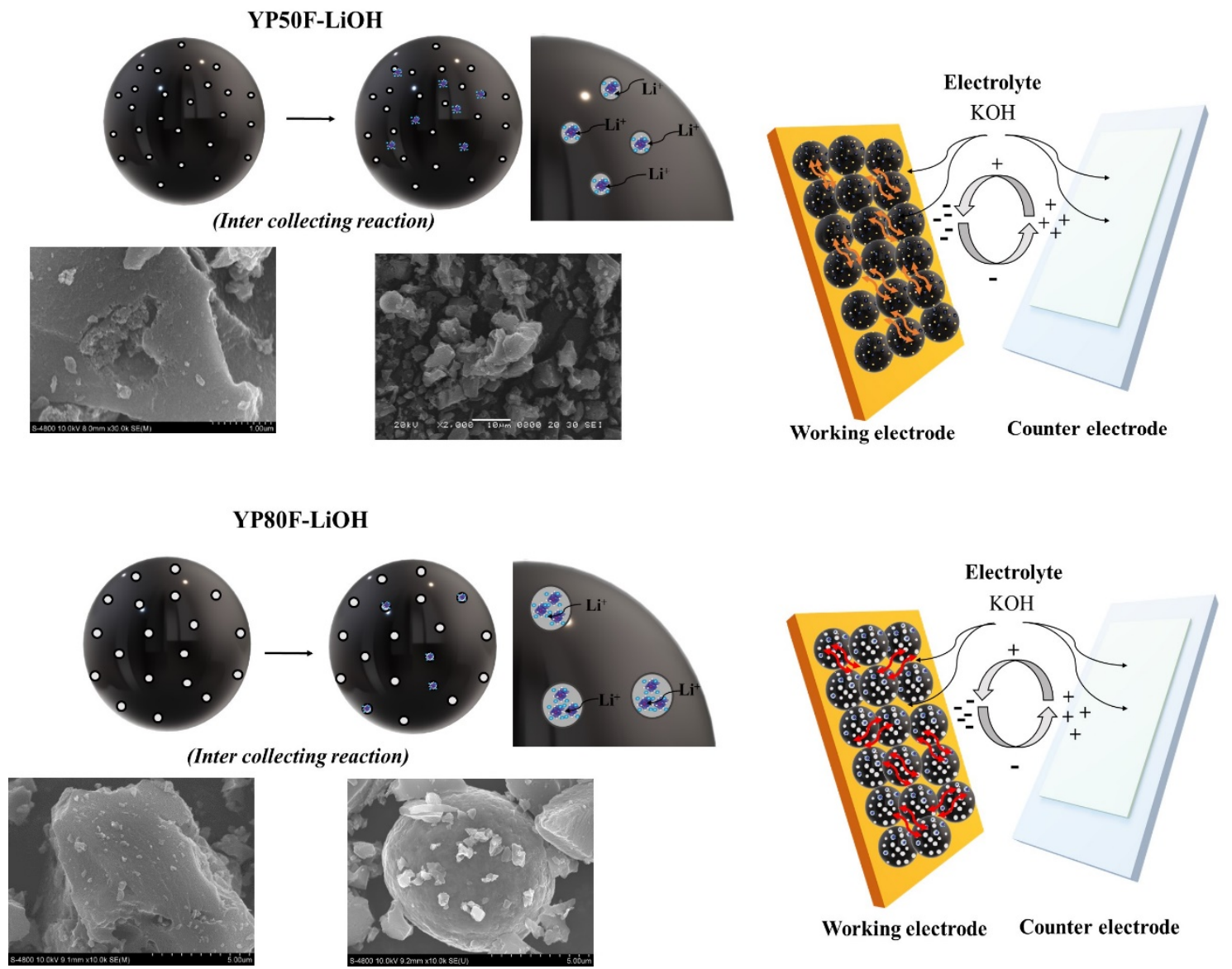

Figure 14. Schematic illustration of the preparation of LiOH-treated carbon material and electrochemical analysis.

\section{Materials and Methods}

\subsection{Chemical Reagents}

The YP50F and YP80F activated carbons were purchased from Kuraray (Tokyo, Japan). And the natural graphite was used in this experiment. The HSAC material was prepared by ball-milling at $350 \mathrm{rpm}$ for $10 \mathrm{~h}$. Lithium hydroxide $(\mathrm{LiOH}, 98 \%)$, sodium hydroxide $(\mathrm{NaOH}$, $97 \%)$, sodium carbonate $\left(\mathrm{Na}_{2} \mathrm{CO}_{3}, 99.9 \%\right)$, sodium bicarbonate $\left(\mathrm{NaHCO}_{3}, 99.7 \%\right)$ and hydrochloric acid ( $\mathrm{HCl}, 36 \mathrm{wt} \%$ ) were purchased from Sigma Aldrich (Munich, Germany). 
Potassium hydroxide $(\mathrm{KOH}, 98 \%)$ were purchased from Samchun Pure Chemical Co., LTD (Gyeonggi-do, Korea).

\subsection{Preparation of Hydrophilic Carbon}

Into a prepared $\mathrm{LiOH}$ solution $(250 \mathrm{~mL})$ was added $20 \mathrm{~g}$ of raw HSAC material. The mix was stirred continuously for $5 \mathrm{~h}$ in room condition and then dried at $100{ }^{\circ} \mathrm{C}$ in an oven to form a powder. The $\mathrm{LiOH}$-treated carbon samples were calcined at $600{ }^{\circ} \mathrm{C}$ for $2 \mathrm{~h}$ in the furnace to purify them and revamp their surface-state. All prepared high-surface-area carbon was grouped into one group, Li-HSAC.

\subsection{Characterization}

The crystal phases of the samples samples were examined between $20=10$ to 70 at a scan rate of $1 \mathrm{~min}^{-1}$ using an X-ray diffraction instrument (SHIMADZU XRD-6000, Nakagyo, Kyoto, Japan) equipped with a Cu Ka X-ray source (1.5406 ̊̊). The surface morphology state of the sample was analyzed by scanning electron microscopy with energy dispersive X-ray spectroscopy (SEM-EDX; JSM-5600 JEOL, Akishima, Tokyo, Japan). The pore volume and surface area were evaluated by the Barrett-Joyner-Halenda $(\mathrm{BJH})$ and Brunauer-Emmett-Teller (BET) methods, respectively, and the whole experiment was conducted on a Micro Active for ASAP 2460 (Norcross, GA 30093, USA). The functional group and chemical bonds were analyzed by using a Fourier-transform infrared spectrometer (FTIR iS5, Thermoscience, Waltham, MA, USA), and the spectral resolution was $3.8 \mathrm{~cm}^{-1}$ background scanning speed and sample scanning speed are 20 scans, respectively. A Raman spectroscopy was performed using a Confocal-Raman imaging system with a $532.13 \mathrm{~nm}$ excitation laser (Renishaw in Via Reflex, NRS-5100, Easton, MD 21601, USA).

\subsection{Boehm Titration}

The surface functional groups of the Li-HSAC nanocomposites were analyzed by a Boehm titration method. A certain mass of sample was added to $0.05 \mathrm{M}$ of three different sodium-based solutions $\left(\mathrm{NaOH}, \mathrm{NaHCO}_{3}, \mathrm{Na}_{2} \mathrm{CO}_{3}\right)$. The mixture was shaken for $24 \mathrm{~h}$ at room temperature. The aliquot was withdrawn by a syringe centrifuge tube and rapidly rotated the sample $(10,000 \mathrm{ppm} / 15 \mathrm{~min})$, and $10 \mathrm{~mL}$ solution was taken by pipette and acidified by adding $0.05 \mathrm{M}$ of $\mathrm{HCl}$ solution. In detail, $0.05 \mathrm{M}$ of $20 \mathrm{~mL} \mathrm{HCl}$ was added into $10 \mathrm{~mL}$ of $\mathrm{NaOH}$ solution, $30 \mathrm{~mL} 0.05 \mathrm{M}$ of $\mathrm{HCl}$ was mixed with $\mathrm{Na}_{2} \mathrm{CO}_{3}$ aliquot and $20 \mathrm{~mL} \mathrm{HCl}$ solution was added to the $\mathrm{NaHCO}_{3}$ aliquot solution. A 2/3 drop of $0.5 \%$ phenolphthalein indicator solution was added into each solutions and centrifuged for $\frac{1}{4} \mathrm{~h}$. In the following back-titration process, $0.05 \mathrm{M} \mathrm{NaOH}$ solution was put-in slowly into the acid-treated mix until the color of the solution turned pink. The titration processes were carried out under ambient temperature conditions. The acidic groups were quantified by Equations (8) and (9) [18]:

$$
\begin{gathered}
{[\mathrm{HCl}] \mathrm{V}_{\mathrm{HCl}}=[\mathrm{NaOH}] \mathrm{V}_{\mathrm{NaOH}}+\left(\frac{\eta_{\mathrm{HCl}}}{\eta_{\mathrm{B}}}[\mathrm{B}] \mathrm{V}_{\mathrm{B}}-\eta_{\mathrm{CSF}}\right) \frac{\mathrm{V}_{\mathrm{a}}}{\mathrm{V}_{\mathrm{B}}}} \\
\eta_{\mathrm{CSF}}=\frac{\eta_{\mathrm{HCl}}}{\eta_{\mathrm{B}}}[\mathrm{B}] \mathrm{V}_{\mathrm{B}}-\left([\mathrm{HCl}] \mathrm{V}_{\mathrm{HCl}}-[\mathrm{NaOH}] \mathrm{V}_{\mathrm{NaOH}}\right) \frac{\mathrm{V}_{\mathrm{b}}}{\mathrm{V}_{\mathrm{a}}}
\end{gathered}
$$

where $[B]$ and $V_{B}$ are the concentration and volume of the reaction base mixed with the carbon, providing the number of moles of reaction base that was available to the carbon surface for reaction with the surface functionalities. $\eta_{\text {CSF }}$ denotes the moles of carbon surface functionalities on the surface of the carbon that reacted with the base during the mixing step. $\mathrm{V}_{\mathrm{a}}$ is the volume of the aliquot taken from the $\mathrm{V}_{\mathrm{B}}$, and $[\mathrm{HCl}]$ and $\mathrm{V}_{\mathrm{HCl}}$ are the concentration and volume of the acid added to the aliquot taken from the original sample. 


\subsection{Cyclic Voltammetry (CV) Test}

The electro-chemical properties of the sample were examined by a cyclic voltammetry (CV) test. The analysis was conducted on a PGP201 Potentiastat (A41A009) by using a three-electrode system. The $\mathrm{CV}$ test was recorded with a $100 \mathrm{mV} \cdot \mathrm{s}^{-1}$ scan rate for 10 cycles. The applied potential range was from $(-300 \mathrm{mV})$ to $(200 \mathrm{mV})$ and the current value range was $(1 \mathrm{~A})$ to $(-1 \mathrm{~A})$. A platinum wire and $\mathrm{Ag} / \mathrm{AgCl}$ were used as a counter and reference electrode. Li-HSAC material as the working electrode. The working electrode was prepared by following a "Doctor blade" method. Ethyl cellulose was used as a binding material and mixed with Li-HSAC in a 1:3 ratio. Then, a few drops of pure ethanol were added, and the resulting mixture was ground and used to veneer the copper foil-top. The size of the copper foil and nickel foil is $2 \times 2 \mathrm{~cm}^{2}$. The Cu-foil current collector enhanced the capacity of the sample; this is due to the conductivity of copper being about $0.6 \mathrm{~S} / \mathrm{cm}$. The uniformity and thickness were metered by adjusting gap between the blade and the substrate. The main principal process of doctor-blading uses a frame with a reservoir coating liquid which is moving relatively to the substrate. When a constant movement between the blade and substrate, the semiliquid mixture spread onto the substrate to make a thin thin-sheet and after drying process it can turn into a gel-layer.

The typical three-electrode assembly was immersed in 5\% $\mathrm{KOH}$ supporting electrolyte solutions. $\mathrm{KOH}$ is a basic electrolytes and it has been the most extensively used because of its high ionic conductivity and it can support the cyclic stability of the working electrode.

\section{Conclusions}

In summary, the working electrode was prepared by a doctor blade method using a $\mathrm{LiOH}$-treated activated carbon with high surface area. The effect of this modification was analyzed by XRD, Raman, SEM-EDX, BET and BJH methods. From the results of material structure analysis, we attributed the unique structure of this material to the connection between an alkali metal and the high surface area of the activated carbon. The surface functional group was analyzed by a Boehm titration-method, which confirmed that the alkali metal-treated carbon material had numerous acidic groups above the target value. The acidic functional group of Li-HSAC enhanced the electrolyte ion-migration through the micro-sized pore structure. The evaluation of the electrochemical properties of Li-HSAC demonstrated that the high electrochemical properties were attributable to the total specific surface area, pore-size distribution, wettability condition and surface modification with an oxidizing agent $(\mathrm{LiOH})$.

Author Contributions: Conceptualization, methodology, formal analysis, and Writing, Z.O. and S.Y.; visualization, I.-J.K.; supervision, W.-C.O. All authors have read and agreed to the published version of the manuscript.

Funding: This research received no external funding.

Institutional Review Board Statement: Not applicable.

Informed Consent Statement: Not applicable.

Data Availability Statement: Data can be made available upon written request to the corresponding author and with a proper justification.

Acknowledgments: This research was supported by Korea Electrotechnology Research Institute (KERI) Primary research program through the National Research Council of Science \& Technology (NST) funded by the Ministry of Science, ICT and Future Planning (MSIP) (No. 21A01035).

Conflicts of Interest: The authors declare no conflict of interest.

Sample Availability: LiOH-treated YP80F, YP50F and graphite are available from the authors. 


\section{References}

1. Jiang, W.; Yu, D.; Zhang, Q.; Goh, K.; Wei, L.; Yong, Y.; Jiang, R.; Wei, J.; Chen, Y. Ternary hybrids of amorphous nickel hydroxidecarbon nanotube-conducting polymer for supercapacitors with high energy density, excellent rate capability, and long cycle life. Adv. Funct. Mater. 2015, 25, 1063-1073. [CrossRef]

2. Zhou, S.Z.; Zhou, G.Y.; Jiang, S.H.; Fan, P.C.; Hou, H.Q. Flexible and refractory tantalum carbide-carbon electro spun nanofibers with high modulus and electric conductivity. Mater. Lett. 2017, 200, 97-100. [CrossRef]

3. Chen, L.; Li, D.; Zheng, X.; Chen, L.; Zhang, Y.; Liang, Z.; Feng, J.; Si, P.; Lou, J.; Ci, L. Integrated nanocomposite of $\mathrm{LiMn}_{2} \mathrm{O}_{4}$ /graphene/carbon nanotubes with pseudocapacitive properties as superior cathode for aqueous hybrid capacitors. J. Electroanal. Chem. 2019, 842, 74-81. [CrossRef]

4. Liu, C.; Ren, Q.Q.; Zhang, S.W.; Yin, B.S.; Que, L.F.; Zhao, L.; Sui, X.L.; Yu, F.D.; Li, X.F.; Gu, D.M.; et al. High energy and power lithium-ion capacitors based on $\mathrm{Mn}_{3} \mathrm{O}_{4} / 3 \mathrm{D}$-graphene as anode and activated polyaniline-derived carbon nanorods as cathode. Chem. Eng. J. 2019, 370, 1485-1492. [CrossRef]

5. Zhang, J.; Wang, Y.; Liao, H.J.; Yang, T.Y.; Chen, Z.; Yan, X.; Zhou, Z.; Lv, H.; Liu, W.W.; Chueh, Y.L. Hierarchical Mn-doped $\mathrm{Fe}_{2} \mathrm{O}_{3} @ \mathrm{rGO}$ hollow core-shell spheres for high-performance hybrid capacitor. Mater. Today Energy 2020, 17, 100388. [CrossRef]

6. Ji, H.M.; Liu, X.L.; Liu, Z.J.; Yan, B.; Chen, L.; Xie, Y.F.; Liu, C.; Hou, W.H.; Yang, G. In Situ Preparation of Sandwich MoO $3 /$ C Hybrid Nanostructures for High-Rate and UltralongLife Supercapacitors. Adv. Funct. Mater. 2015, 25, 1886-1894. [CrossRef]

7. Yu, M.H.; Zeng, Y.; Han, Y.; Cheng, X.Y.; Zhao, W.X.; Liang, C.L.; Tong, Y.X.; Tang, H.L.; Lu, X.H. Valence-Optimized Vanadium Oxide Supercapacitor Electrodes Exhibit Ultrahigh Capacitance and Super-Long Cyclic Durability of 100 000 Cycles. Adv. Funct. Mater. 2015, 25, 3534-3540. [CrossRef]

8. Yang, C.C.; Sun, W.C.; Kumar, A.; Pattanayak, B.; Tseng, T.Y. Templating synthesis of nickel cobaltite nanoflakes and their nanocomposites for making high-performance symmetric supercapacitors. Mater. Today Energy 2019, 14, 100356. [CrossRef]

9. Shoyebmohamad, F.; Shaikh Fouzia, F.M.; Shaikh, A.V.; Shaikh Mohd, U.; Abdullah, M.; Al-Enizi Habib, M.P. Electrodeposited more-hydrophilic nano-nest polyaniline electrodes for supercapacitor application. J. Phys. Chem. Solids 2021, $149,109774$. [CrossRef]

10. Long, C.; Chen, X.; Jiang, L. Porous layer-stacking carbon derived from in-built template in biomass for high volumetric performance supercapacitors. Nano Energy 2015, 12, 141-151. [CrossRef]

11. Mousavi-Kamazani, M.; Rahmatolahzadeh, R.; Shobeiri, S.A.; Beshkar, F. Sonochemical synthesis, formation mechanism, and solar cell application of tellurium nanoparticles. Ultrason. Sonochem. 2017, 39, 233-239. [CrossRef] [PubMed]

12. Nguyen, T.T.; Asakura, Y.; Okada, N.; Koda, S.; Yasuda, K. Effect of ultrasonic cavitation on measurement of sound pressure using hydrophone. Jpn. J. Appl. Phys. 2017, 56. [CrossRef]

13. Wang, Z.; Yin, C. State-of-the-art on ultrasonic oil production technique for EOR in China. Ultrason. Sonochem. 2017, 38, 553-559. [CrossRef] [PubMed]

14. Hou, J.; Cao, C.; Ma, X. From rice bran to high energy density supercapacitors: A new route to control porous structure of 3D carbon. Sci. Rep. 2014, 4, 7260. [CrossRef]

15. Tzanakis, I.; Lebon, G.S.B.; Eskin, D.G.; Pericleous, K.A. Characterizing the cavitation development and acoustic spectrum in various liquids. Ultrason. Sonochem. 2017, 34, 651-662. [CrossRef] [PubMed]

16. Reddy, A.P.; Rao, P.N.; Reddy, M.C.S.; Rao, B.A.; Veeraiah, N. Second harmonic generation and spectroscopic characteristics of $\mathrm{TiO}_{2}$ doped $\mathrm{Li}_{2} \mathrm{O}-\mathrm{Al}_{2} \mathrm{O}_{3}-\mathrm{B}_{2} \mathrm{O}_{3}$ glass matrix. Appl. Phys. A 2020, 126. [CrossRef]

17. Zhang, Y.; Qin, L.; Cui, Y.; Liu, W.; Liu, X.; Yang, Y.Z. A hydrophilic surface molecularly imprinted polymer on a spherical porous carbon support for selective phenol removal from coking wastewater. New Carbon Mater. 2020, 34, 220-231. [CrossRef]

18. Zambaga, O.; Kamrun, N.F.; Rafat, M.N.; Ryu, J.; Yang, S.H.; Kim, I.J.; Oh, W.C. Surface Modification and Electrochemical Performance of $\mathrm{KMnO}_{4}$-Ultra-surface Area Activated Carbon (USAC) Composites as Cathode Material. J. Korean Ceram. Soc. 2020, 6. [CrossRef]

19. Schönherr, J.; Buchheim, J.R.; Scholz, P.; Adelhelm, P. Boehm Titration Revisited (Part I): Practical Aspects for Achieving a High Precision in Quantifying Oxygen-Containing Surface Groups on Carbon Materials. J. Carbon Res. 2018, 4, 21. [CrossRef]

20. Zhang, D.D.; Wang, J.L.; He, C.; Wang, Y.; Guan, T.; Zhao, J.; Qiao, J.; Li, K. Rational surface tailoring oxygen functional groups on carbon spheres for capacitive mechanistic study. ACS Appl. Mater. Interfaces 2019, 11, 13214-13224. [CrossRef]

21. Miao, Z.Y.; Huang, Y.; Xin, J.P.; Su, X.; Sang, Y.; Liu, H.; Wang, J.J. High-performance symmetric supercapacitor constructed using carbon cloth boosted by engineering oxygen-containing functional groups. ACS Appl. Mater. Interfaces 2019, 11, 18044-18050. [CrossRef] [PubMed]

22. Jiang, L.L.; Sheng, L.Z.; Long, C.L.; Wei, T.; Fan, Z. Functional pillared graphene frameworks for ultrahigh volumetric performance supercapacitors. Adv. Energy Mater. 2015, 5, 1500771. [CrossRef]

23. Lee, J.; Abbas, M.A.; Bang, J.H. Exploring the capacitive behavior of carbon functionalized with cyclic ethers: A rational strategy to exploit oxygen functional groups for enhanced capacitive performance. ACS Appl. Mater. Interfaces 2019, 11, 19056-19065. [CrossRef]

24. Fan, L.Z.; Qiao, S.Y.; Song, W.L.; Wu, M.; He, X.; Qu, X. Effects of the functional groups on the electrochemical properties of ordered porous carbon for supercapacitors. Electrochim. Acta 2013, 105, 299-304. [CrossRef]

25. Xi, L.; Yang, J.; Pei, W.; Yan, M.; Wen, L.; Zheng, L.; Ru, Y.; Yu, D.; Xin, Z.; Yong, C. Effect of the oxygen functional groups of activated carbon on its electrochemical performance for supercapacitors. New Carbon Mater. 2020, 35, 232-243. [CrossRef] 
26. Yanan, X.; Xiaofeng, W.; Cuihua, A.; Yijing, W.; Lifang, J.; Huatang, Y. Effect of the length and surface area on electrochemical performance of cobalt oxide nanowires for alkaline secondary battery application. J. Power Source 2014, 272, 703-710. [CrossRef]

27. Venezuela, P.; Lazzeri, M.; Mauri, F. Theory of double-resonant Raman spectra in graphene: Intensity and line shape of defect-induced and two-phonon bands. Phys. Rev. B 2011, 84, 035433. [CrossRef]

28. Kumar, B.; Thomas, D.; Kumar, J. Space-Charge-Mediated Superionic Transport in Lithium Ion Conducting Glass-Ceramics. J. Electrochem. Soc. 2009, 156, A506-A513. [CrossRef]

29. Neetu, S.; Neha, G.; Rama, K. Experimental corroboration of the theory of chronoamperometry at high roughness electrode for reversible charge transfer. J. Electroanal. Chem. 2017, 788, 83-90. [CrossRef]

30. Zang, X.N.; Shen, C.W.; Sanghadasa, M.; Lin, L.W. High-Voltage Supercapacitors Based on Aqueous Electrolytes. Chemelectrochem 2019, 6, 976-988. [CrossRef]

31. See, D.M.; White, R.E. Temperature and Concentration Dependence of the Specific Conductivity of Concentrated Solutions of Potassium Hydroxide. J. Chem. Eng. Data 1997, 42, 1266-1268. [CrossRef]

32. Zhong, C.; Deng, Y.; Hu, W.; Qiao, J.; Zhang, L.; Zhang, J. A review of electrolyte materials and compositions for electrochemical supercapacitors. Chem. Soc. Rev. 2015, 44, 7484-7539. [CrossRef] [PubMed]

33. Yan, J.; Wang, Q.; Wei, T.; Fan, Z. Supercapacitors: Recent Advances in Design and Fabrication of Electrochemical Supercapacitors with High Energy Densities. Adv. Energy Mater. 2014, 4, 1300816. [CrossRef]

34. Zhang, X.; Wang, X.; Jiang, L.; Wu, H.; Wu, C.; Su, J. Effect of aqueous electrolytes on the electrochemical behaviors of supercapacitors based on hierarchically porous carbons. J. Power Source 2012, 216, 290-296. [CrossRef]

35. Mao, Z.X.; Zhang, W.; Wang, M.J.; Peng, L.; Hong, W.; Deng, J.; Li, J.; Wei, Z. Enhancing rate performances of carbon-based supercapacitors. Chem. Select 2019, 4, 6827-6832. [CrossRef]

36. Zhi, M.J.; Yang, F.; Meng, F.K.; Li, M.; Manivannan, A.; Wu, N. Effects of pore structure on performance of an activated-carbon supercapacitor electrode recycled from scrap waste tires. ACS Sustain. Chem. Eng. 2014, 2, 1592-1598. [CrossRef]

37. Xie, Y.B.; Qiao, W.M.; Zhang, W.Y.; Sun, G.W.; Ling, L.C. Effect of the surface chemistry of activated carbon on its electrochemical properties in electric double layer capacitors. New Carbon Mater. 2010, 25, 248-254. [CrossRef] 